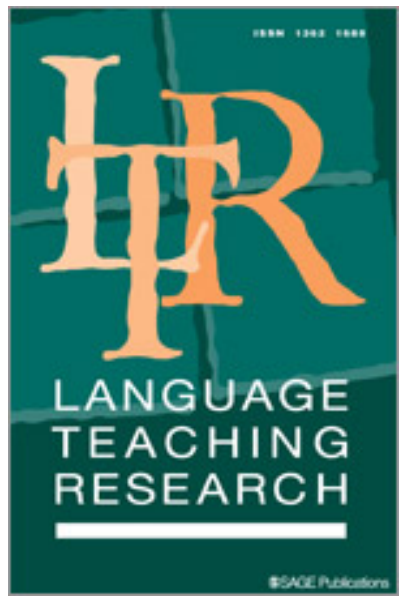

\title{
Social Psychological Accounts of Peer Emotion Transfer in EFL Classrooms: A Doubly Latent Multilevel Analysis
}

\begin{tabular}{|c|l|}
\hline Journal: & Language Teaching Research \\
\hline Manuscript ID & LTR-19-0548.R2 \\
\hline Kanuscript Type: & Full Research Article \\
\hline Abstract: & $\begin{array}{l}\text { emotion, interpersonal affect transfer, appraisal, language, classroom, } \\
\text { peer }\end{array}$ \\
& $\begin{array}{l}\text { Based on theories of emotion contagion and social appraisal in } \\
\text { interpersonal affect transfer and the control-value theory of achievement } \\
\text { emotions, the present study examined associations between students' } \\
\text { perceptions of peer emotions and their own self-perceived emotions in } \\
\text { English as a foreign language (EFL) classrooms. Data were collected } \\
\text { from 103 seventh to ninth grade classrooms (N = 3,643) using self- } \\
\text { report questionnaires. Doubly latent multilevel structural equation } \\
\text { modeling showed that perceived peer enjoyment, anxiety and boredom } \\
\text { and students' corresponding emotions for language learning were } \\
\text { positively related and that the effects of perceived peer enjoyment, } \\
\text { anxiety and boredom on corresponding student emotions were mediated } \\
\text { by control and value appraisals at the individual level. At the class level, } \\
\text { however, the mediation effects were only significant for control appraisal } \\
\text { as a mediator of effects on anxiety and value appraisal as a mediator of } \\
\text { effects on boredom. Effects were robust across grade level, gender and } \\
\text { previous language achievement. The discussion centers on the practical } \\
\text { implications of peer emotion interactions for promoting foreign language } \\
\text { development in classroom instruction. }\end{array}$ \\
\hline
\end{tabular}

\section{SCHOLARONE" Manuscripts}




\title{
Social Psychological Accounts of Peer Emotion Transfer in EFL Classrooms: A Doubly Latent Multilevel Analysis
}

\begin{abstract}
Based on theories of emotion contagion and social appraisal in interpersonal affect transfer and the control-value theory of achievement emotions, Tthe present study examined associations between students' perceptions of peer emotions and their individuatown selfperceivedption ofstudent emotions in theirEnglish as a foreign language (EFL) classrooms.Based on theories of emotion contagion and social appraisal in interpersonal affect transfer and the control value theory of achievement emotions, the atthors hypothesized (a) that peer enjoyment, anxiety and boredom within FL classrooms are positively linked with students' eorresponding enjoyment, anxiety and boredom, and (b) that students' control and valueappraisals mediate the relationships between peer and student emotions. Data were collected from 103 seventh- to ninth grade classrooms $(N=3,643)$ using self-report questionnaires. $\underline{\text { Doubly latent }} M$ multilevel structural equation modeling showed that perceived peer enjoyment, anxiety and boredom and students' corresponding emotions for language learning were positively related and that the effects of perceived peer FLenjoyment, anxiety and boredom-emotions on corresponding student emotions were mediated by control and value appraisals at the individual level. At the class level, however, the mediation effects were only significant for control appraisal as a mediator of effects on anxiety and value appraisal as a mediator of effects on boredom. Effects were robust across grade level, gender and previous language achievement. The discussion centers on the highlights thepractical
\end{abstract}


implications of rele of classroem based peer emotion interactions infor promoting foreign language FL development in classroom instruction.

Keywords: emotion, peer, interpersonal affect transfer, appraisal, language, classroom

\section{Introduction}

Emotions are of critical importance for students' foreign language (FL) learning and achievement (Dewaele andㅌ MacIntyre, 2014). Recent research has documented that both positive emotions (e.g. enjoyment, hope and pride) and negative emotions (e.g. anxiety, shame and boredom) can affect foreign/second language engagement and performance by influencing learners' interest, motivation, effort, self-regulation of learning, and the availability of cognitive resources for language tasks (Dewaele et al., 2018; Lee, 2014; Saito et al., 2018; Shao et al., 2020b; Teimouri, 2017). Previous research tended to address these emotions from an individualistic perspective; however, it can be assumed that students' FL emotions are not experienced in a social vacuum, but rather are influenced by other people such as peers and teachers in the micro-context of language classrooms (Shao et al., 2020a). The need to study the emotional interactions among peers in the FL classroom has become even more significantee given the fact that students spend the majority of their time with peers in their school life.

$\underline{\text { Social psychological theories of emotion contagion and social appraisal offers two }}$ useful accounts for explaining the phenomenon of peer emotion transmission in FL classrooms (Parkinson \& Manstead, 2015). Whereas emotion contagion postulates that a 
person's emotions can be automatically infected by their social partners' emotional states (Hatfield, Cacioppo, \& Rapson, 1994); social appraisal suggests that the influence of other people's emotions on a person depends on the relevant person's appraisals of the meaning of $\underline{\text { their social partners' emotions (Parkinson, 2011). In educational research, the control-value }}$ $\underline{\text { theory (CVT) of achievement emotions posits that appraisals of achievement-related control }}$ and value are the primary antecedents of students' emotions towards learning activities and outcomes (Pekrun, 2006). Both control and value appraisals are essential for an emotion to be instigated (Pekrun \& Perry, 2014). Moreover, the CVT implies that control and value appraisals can mediate the effects of classroom features (e.g. teachers, peers and instruction quality) on students' achievement emotions (Pekrun, 2006). However, these assumptions have rarely been examined in the foreign language classroom. Combining the social appraisal and CVT perspectives raises the possibility that peer-to-peer emotional transfer is mediated by the control and value appraisals that are inferred from observed peer emotions. For example, observing classmates' enjoyment leads to the inference that they value their current learning activities, leading pupils to value and hence enjoy those activities too. However, studies of the causes and outeomes of emotions other than anxiety are still largely lacking in the field of second language acquisition (SLA). Given the relevance of different emotions for FL learning and performance, it is important to enhance our knowledge of the antecedents of these emotions, especially appraisals, which have been seen as the primary cause of emotions (Goetz et al., 2010). Prems these antecents from an individualistic perspetive (King and Gaerlan, 2014; Shao, Yu,

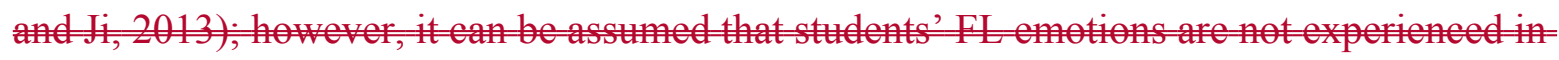




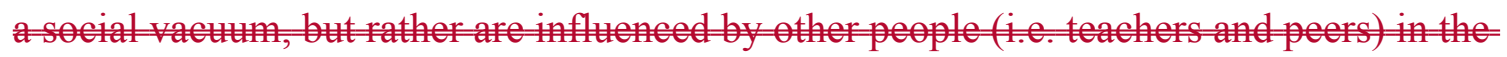

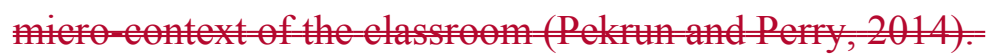

Although atvery few studies have explored the impact of classroom environment on students' FL-emotions in the FL context (Cao, 2014; Gkonou, \& Miller, 2019; Khajavy et al., 2016; Peng and Woodrow, 2010), these studies have often treated teacher and peer variables at the individual level as if language learners and teachers are independent offrom each other. Students studying in the same class have the same teachers, performete the same activities at the same time, and share the same classroom atmosphere, thus, this represents a $\underline{\text { nested structure of data with students at the individual level (L 1) and class at the group level }}$ $\underline{2 \text { (L2) (Khajavy, MacIntyre, \& Barabadi, 2018). Interpreting student--level variables as }}$ though they reflect class--level variables is a very common mistake in educational and $\underline{\text { language research (Cunnings, 2012; Marsh et al., 2012). Analyzing data at a single student }}$ level confounds the effects of the individual student and the classroom and implicitly assumes that the effects observed atim one level generalize to another (Marsh et al., 2012). This statistical issue, however, can be addressed directly by using multilevel analysis and its recent development, doubly latent multilevel analysis wherein both student and class levels effects are estimated. the influence of these variables on FL learners' emotions need to beaddressed at both individual and class levels (Khajavy, MacIntyre, and Barabadi, 2018).

The present study extends previous research by considering the informational and affective consequences of perceived peer emotions on individual language FL-learners' emotions. In particular, we consider two ways in which perceived peers' FL enjoyment, anxiety and boredom may influence students' own corresponding emotions towards 
language learning, the first based on social appraisal (Parkinson $\underline{\&}$ Manstead, 2015), and the second based on emotion contagion (Hatfield et al.,-Cacioppe, and Rapson, 1994).

Moreover, based on the CVT control-value theory of achievement emotions-(Pekrun, 2006), we consider two types of cognitive appraisals, namely, perceived control and perceived value, as potential mediators in the process of social appraisal. Furthermore, benefiting from recent methodological advances in doubly latent multilevel analyses (Marsh et al., 2012), we investigated how students' individuat self-perceivedption of FL emotions are influenced by their perceptions of peer emotionseur hypotheses at both the student level and the classroom level in order to acquire a more comprehensive understanding of how such a mechanism functions in the FL context.

\section{$\underline{\text { Emotion Contagion and Social Appraisal in Emotion Transfer }}$}

Emotion contagion and social appraisal are two influential accounts of interpersonal affect $\underline{\text { transfer in social psychology (Parkinson, 2011). Emotion contagion postulates a natural }}$ $\underline{\text { tendency to mimic other people's expressions and postural changes during interpersonal }}$ interaction. Self-perception of these copied movements in turn produces corresponding emotional experiences via interceptive feedback processes (Hatfield et al., 1994). For example, we may simply feel happy after interacting with a cheerful person. By contrast, social appraisal theory suggests that one person's emotion affects a second person's emotion because of its effects on the second person's appraisals. In particular, individuals may take other people's feelings into account when arriving at evaluations of the emotional significance of what is happening (Parkinson \& Manstead, 2015). For instance, we may 
become more anxious about an event when our companion's anxiety makes us aware of risks that we had not previously considered.

The distinction between these two perspectives hinges on the role of appraisals in interpersonal affect transfer. Social appraisal occurs because someone else's perceived affect carries information that alters our appraisal of the meaning of events and subsequent emotions. This implies that social appraisal may serve as the mediator in the influence of other people's emotions on our own emotions. In emotion contagion, however, we catch another person's affect automatically and without necessarily registering its personal significance (Parkinson \& Simons, 2009).

Ample evidence already supports the operation of these two processes in emotion $\underline{\text { transfer (Moody et al., 2007; Neumann \& Strack, 2000; Parkinson \& Simons, 2009). For }}$ example, Neumann and Strack (2000) attempted to test mood contagion in a series of experiments where participants listened to recordings of a happy, neutral, or sad voice. Mood was rated as better after exposure to the happy voice, but there were no corresponding $\underline{\text { effects of explicit registration of the other's expressed affect or awareness that affect had }}$ been influenced. On the other hand, Parkinson and Simons' (2009) diary research investigated interpersonal emotion transfer in everyday decision-making. Participants' anxiety about impending decisions was significantly affected by the reported anxiety of another person present at the time, and this affect transfer was partially mediated by appraisals of risk and importance.

Although these two perspectives have not been examined previously in the FL context, it seems likely that they are equally applicable in language classrooms (Shao et al., 2020a). 
For example, students may get excited when watching classmates enjoy using the FL to communicate with the teacher without thinking about the reasons behind their peers' enjoyment (contagion). This shared enjoyment may also change students' perception of value or sense of self-efficacy about speaking the target language, which may in turn have positive effects on their own enjoyment of practicing the FL orally (appraisal). By contrast, $\underline{\text { they may catch peers' anxiety immediately after seeing them speaking nervously in front of }}$ $\underline{\text { the language class. This may lead them to worry about possible negative evaluations of }}$ mistakes and undermine their confidence and interest in public speaking, which may further exacerbate their language anxiety. These assumptions are in line with Pekrun's (2006) proposition that the classroom environment can shape students' achievement-related appraisals and emotions.

\section{Control and Value Appraisals in Achievement Emotions}

$\underline{\text { Contemporary theories of emotion emphasize the pivotal role of cognitive appraisals for }}$ eliciting emotions (e.g. Scherer, 2013). In the same vein, the control-value theory of achievement emotions proposes that individuals experience specific achievement-related emotions when they feel in control, or out of control, of achievement activities and outcomes $\underline{\text { that are subjectively important, implying that control and value appraisals are the proximal }}$ determinants of these emotions (Pekrun, 2006; Pekrun \& Perry, 2014). High perceived $\underline{\text { control and positive perceived value of achievement activities and outcomes are assumed to }}$ $\underline{\text { elicit positive emotional experiences such as enjoyment or pride, whereas low control and }}$ $\underline{\text { negative value are expected to elicit negative emotions such as anxiety or boredom. So far, a }}$ 
number of studies have confirmed that positive achievement emotions are positively associated with students' control and positive value appraisals, while the opposite pattern has generally been found for negative achievement emotions (Goetz et al., 2010; Pekrun et al., 2011; Shao et al., 2020b).

Moreover, the control-value framework postulates that the affective impact of the social environment on achievement emotions is mediated by control and value appraisals (Pekrun, 2006). Accordingly, it is assumed that features of the learning environment that provide $\underline{\text { information related to controllability and academic values are of crucial importance for }}$ $\underline{\text { students' emotions. Consistent with this assumption, recent research has shown that a }}$ classroom environment conveying positive relationships, enjoyment and mastery goal orientation positively predicts students' academic self-efficacy, engagement and $\underline{\text { achievement and negatively predicts their anxiety at both individual and classroom levels }}$ (Arens, Morin, \& Watermann, 2015; Frenzel et al., 2018; Reyes et al., 2012). However, this $\underline{\text { research has focused exclusively on domain-general emotions or students' math-related }}$ $\underline{\text { emotions, and has neglected students' emotions in language learning. }}$

$\underline{\text { In the present FL context, perceived peer emotions provide meaningful signals }}$ reflecting their appraisals of the language learning events. They may influence students' emotions either directly as a result of emotion contagion (Hatfield et al., 1994) or by affecting students' control-value appraisals (Pekrun \& Perry, 2014). Appraisal mediation would be consistent with the social appraisal account of interpersonal emotional influence in which the integration of information gleaned from others' emotions into one's own evaluation of an emotional situation plays an important role (Parkinson \& Simons, 2009). To 
date, there is a lack of empirical evidence documenting the relationships between perceptions of peer emotions and students' self-perceived appraisals and emotions in learning in general and FL learning in particular.

\section{Enjoyment, Anxiety and Boredom}

Research has shown that students experience a wide range of positive and negative emotions in general education (Frenzelet a1., 2018; Goetz et al., 2010; Pekrun et al., 2011), but studies examining diverse emotions other than anxiety are still at the nascent stage in second language research (Dewaele et al., 2018; Shao et al., 2020). With the introduction of positive psychology int the field of SLA (see MacIntyre, Gregersen, \& Mercer, 2019), Dewaele and MacIntyre (2014) began to emphasize the role of positive emotions in general, and enjoyment in particular, in promoting and facilitating language development. Early studieshave found that FL enjoyment positively correlated with learners' motivation, interest, effort and performance and negatively correlated with their FL anxiety (Satio et al., 2018; Shirvan\& Taherian, 2018; Teimouri, 2017). Importantly, measures of classroom atmosphere such asateacher's FL accent, frequeney of FL use, friendliness and students' attitudes towards their FL teacher were shown to be more predictive of FL enjoyment than FL anxiety (Dewaele et a1., 2018; 2019). These findings suggest a need for further studies to examine a broader range more types of emotions in SLA as well as the influence of more classroem specific antecedents including those relating to peers on students' FL emotions. Anxiety has been the most-studied emotion in the SLA literature (see Teimouri, Goetze, \& Plonsky, 2019). FL anxiety can be defined as "worry and negative emotional reaction 
aroused when learning or using a second language" (MacIntyre \& Gardner, 1994). Anxiety arousal distracts attention, causes diminished task-relevant cognition, and can affect theprocessing of L2 stimuli at all stages of language acquisition (see MacIntyre \& Gardner, 1994). To date, the majority of research evidence suggests a moderately significant moderate negative associations between anxiety and $\mathrm{L} 2$ performance (see Teimouri et a1., 2019). Research has also shown that individual antecedents such as learners' demographics, eharacteristies, and task related competence and value appraisals are important predictors of FL anxiety (Phung, 2017; Sardegna, Lee, \& Kusey, 2018; Shao, Yu, \& Ji, 2013). At the elass level, Khajavy et al.'s (2018) recent study has demonstrated that peer and teacher support positively predicts students' FL enjoyment, but negatively prediets their FL anxiety. Boredom is an emotion that is among the most frequently experienced in the classroom (Pekrun et al., 2014); however, it has seldom been examined in the second language context. FL boredom can be specified as “an unpleasant feeling characterized by lack of cognitive stimulation, low physiological arousal and a sense of disengagement toward the language tasks" (Shaø, Pekrun, \& Nicholsøn, 2019). Studies in educational research have shown that boredom has no less deleterious effects than anxiety on students' learning and performance(see Frenzel et al., 2007; Pekrun et al., 2014). Very recently, a few pioneering studies have begunan to explore possible correlates of boredom in the FL classroom (e.g., Pawlak et al., 2020). Preliminary results showed that factors such as disengagement, monotony, repetitiveness and lack of satisfaction and challenge contributed to students' boredom in language classes, and low achievers also reported higher level of proneness to boredom than high achievers (Pawlak et al., 2020). The need for further research investigatingto 


\begin{abstract}
investigate boredom in the FL context has become apparent given the fact that SLA is a gradually developing process necessitating long term efforts, motivation, patience, interests, concentration and the like (MacIntyre et al., 2019).
\end{abstract}

\title{
Emotion Transmission in the FL Classroom
}

Social-cognitive learning theories (Bandura, 1977; Pekrun, 2006) suggest that students' emotions are likely to be influenced by their peers' or teachers' thoughts, feelings and behaviors. Students may learn that a language-learning task is interesting by registering a teacher's enthusiasm, or by observing their peers' enjoyment of the learning content. By contrast, they may feel anxious about an FL exam due to teachers' past criticism, or as a result of watching peers' worried faces. In language classrooms, the need for students to communicate and interact with one another is greater than in other subjects due to the communicative demands of language acquisition. However, previous FL research has only tapped relations between teacher and student emotions, leaving the influence of peer emotions largely neglected. For example, studies have reported that teachers' foreign language anxiety (FLA) directly increases students' anxiety (Horwitz, 1996); whereas teachers' emotional warmth and positive characteristics (e.g. humor, friendliness) enhance students' positive feelings toward language learning (Borg, 2006; Dewaele, Magdalena, \& $\underline{\text { Saito, 2019). }}$

Despite language researchers' lack of attention to the emotional influence offrom peer emotions, some laboratory and field studies provide support for its operation. Fischer et al. (2004) investigated the impact of peers' emotional reactions on participants' own emotions 
in a feedback manipulation task. Results revealed that when others expressed anger, participants reported more intense anger themselves, and when others expressed sadness, participants reported more intense sadness themselves. The findings also showed that the extent of emotional assimilation depended on participants' interpersonal orientation and the extent to which others' emotions were recognized and processed. In a classroom setting, Delvaux et al. (2015) examined the influence of peer emotions on individual psychology students' emotions in small group tasks. Their results showed that individual students' anger and gratitude about the class assignments were influenced by their group members' correspomding collective emotions. Moreover, the emotion norms perceived by students within groups also shaped their emotions supporting the social appraisal account of emotion transmission (Parkinson, 202019).

Taken together, these findings suggest that students tend to experience and show similar emotions when they interact with each other in a shared situation. Importantly, this emotional assimilation is not simply the result of automatic mimicry, but rather involves using peers' emotions as a source of information about appraisal of emotional events (Fischer et al., 2004). However, these studies only investigated affect transfer among a small number of participants in group tasks, limiting the generalizability of their results.

Furthermore, although Delvaux et al.'s (2015) study employed multi-level analysis to control for clustering effects at the group level, it did not take into account the influence of perceived peer emotions on individual students' emotions at both class and individual levels. The study also used manifest variables to measure perceived peer emotions and student selfperception of emotions, which led to an underestimation of the correlations between them 
(Morin et al., 2014). To address these deficits, we conducted a large-scale quantitative study using doubly-_latent multilevel analysis to examine the emotion transfer among Chinese middle-school students in their English classrooms.

\section{Enjoyment, Anxiety and Boredom}

$\underline{\text { Research has shown that students experience a wide range of positive and negative emotions }}$ in general education (Frenzel et al., 2018; Goetz et al., 2010; Pekrun et al., 2011), but studies examining emotions other than anxiety are still at the nascent stage in second language research (Dewaele et al., 2018; Shao et al., 2020b). With the introduction of positive psychology to the field of SLA (see MacIntyre, Gregersen, \& Mercer, 2019), Dewaele and MacIntyre (2014) began to emphasize the role of positive emotions in general, and $\underline{\text { enjoyment in particular, in promoting and facilitating language development. Early studies }}$ have found that FL enjoyment positively correlated with learners' motivation, interest, effort and performance and negatively correlated with their FL anxiety (Satio et al., 2018; Shirvan $\underline{\text { \& Taherian, 2018; Teimouri, 2017). Importantly, measures of classroom atmosphere such as }}$ a teacher's FL accent, frequency of FL use, friendliness and students' attitudes towards their FL teacher were shown to be more predictive of FL enjoyment than FL anxiety (Dewaele et al., 2018; 2019). These findings suggest a need for further studies to examine a broader range of emotions in SLA as well as the influence of more classroom-specific antecedents including those relating to peers on students' FL emotions.

Anxiety has been the most-studied emotion in the SLA literature (see Teimouri, Goetze, $\underline{\text { \& Plonsky, 2019). FL anxiety can be defined as "worry and negative emotional reaction }}$ 
aroused when learning or using a second language" (MacIntyre \& Gardner, 1994, p. 284).

Anxiety-related arousal distracts attention, causes diminished task-relevant cognition, and $\underline{\text { can affect the processing of L2 stimuli at all stages of language acquisition (see MacIntyre \& }}$ Gardner, 1994). To date, the majority of research evidence suggests a significant moderate negative association between anxiety and L2 performance (see Teimouri et al., 2019). $\underline{\text { Research has also shown that individual antecedents such as learners' demographics, }}$ characteristics, and task-related competence and value appraisals are important predictors of FL anxiety (Phung, 2017; Sardegna, Lee, \& Kusey, 2018; Shao, Yu, \& Ji, 2013). At the class level, Khajavy et al.'s (2018) recent study has demonstrated that peer and teacher support positively predicts students' FL enjoyment, but negatively predicts their FL anxiety. Boredom is an emotion that is among the most frequently experienced in the classroom (Pekrun et al., 2014); however, it has seldom been examined in the second language context. FL boredom can be specified as "an unpleasant feeling characterized by lack of cognitive stimulation, low physiological arousal and a sense of disengagement toward the language tasks" (Shao, Pekrun, \& Nicholson, 2019,p. 4). Studies in educational research have shown that boredom has no less deleterious effects than anxiety on students' learning and performance (see Frenzel et al., 2007; Pekrun et al., 2014). Very recently, a few pioneering $\underline{\text { studies have begun to explore possible correlates of boredom in the FL classroom (e.g., }}$ Pawlak et al., 2020). Preliminary results show that factors such as disengagement, monotony, repetitiveness and lack of satisfaction and challenge contribute to students' $\underline{\text { boredom in language classes, and low achievers also report higher level of proneness to }}$ boredom than high achievers (Pawlak et al., 2020). The need for further research 
investigating boredom in the FL context has become apparent given the fact that SLA is a gradually developing process necessitating long-term efforts, motivation, patience, interests, concentration and the like (MacIntyre et al., 2019).

\section{Emotion Contagion and Social Appraisal in Emotion Transfer}

Emotion contagion and social appraisal are two influential accounts of interpersonat affect transfer in social psychology (Parkinsen, 2011). Emotion contagion postulates a natural tendency to mimic other people's expressions and postural changes during interpersonal interaction. Self perception of these copied movements in turn producescorrespending emotional experiences via interceptive feedback processes (Hatfield et al., 1994). For example, we may simply feel happy after interacting with a cheerful person. By contrast, social appraisal theory suggests that one person's emotion affects a second person's emotion because of its effects on the second person's appraisals. In particular, individuals may take other people's feelings into account when arriving at evaluations of the emotional significance of what is happening (Parkinson and Manstead, 2015). For instance, we may become more anxious about an event when our companion's anxiety makes us aware of risks that we had not previously considered. The distinction between these two perspectiveshinges on the role of appraisals in interpersonal affect transfer. Social appraisal occursbecause someone else's perceived affect carries information that alters our appraisal of the meaning of events and subsequent emotions. This implies that social appraisal may serve as the mediator in the influence of other people's emotions on our own emotions. In emotioneontagion, however, we catch another person's affect automatically and without necessarily 
registering its personal-significance (Parkinson and Simons, 2009).

Ample evidence already supports the operation of these two processes in emotiontransfer (Moody et al., 2007; Neumann and Strack, 2000; Parkinson and Simons, 2009). For example, Neumann and Strack (2000) attempted to test mood contagion in a series of experiments where participants listened to recordings of a happy, neutral, or sad voice. Mood was rated as better after exposure to the happy voice, but there were no corresponding effects of explicit registration of the other's expressed affect or awareness that affect hat been influenced. On the other hand, Parkinson and Simons' (2009) diary researchinvestigated interpersonal emotion transfer in everyday decision-making. Participants' anxiety about impending decisions was signifieantly affected by the reported anxiety of another person present at the time, and this affect transfer was partially mediated by appraisals of risk and importance.

Although these perspectives have not been examined previously in the FL context, it seems likely that they are equally applicable in language classrooms. For example, students may get excited when watching classmates enjoy using the FL to communicate with the teacher without thinking about the reasons behind their peers' enjoyment (contagion). This shared enjoyment may also change students' perception of value or sense of selfefficacy about speaking the target language, which may in turn have positive effects on their own enjoyment of practicing the FL orally (appraisal). By contrast, they may cateh peers' anxiety immediately after seeing them speaking nervously in front of the language class. This may lead them to worry about possible negative evaluations of mistakes and undermine their confidence and interest in public speaking, which may further exacerbate their 
langulage anxiety. These assumptions are in line with Pekrun's (2006) proposition that the elassroom environment can shape students' achievement related appraisals and emotions.

\section{Controland Value Appraisals in Achievement Emotions}

Control-value theory (Pekrun, 2006; Pekrun and Perry, 2014) proposes that individualsexperience specific achievement related emotions when they feel in control, or out of control, of achievement activities and outcomes that are subjectively important, implying that control and value appraisals are the proximal determinants of these emotions. High perceived control and positive perceived value of achievement activities and outcomes are assumed to elicit positive emotional experiences such as enjoyment or pride, whereas low control and negative value are expected to elicit negative emotions such as anxiety or boredom. So far, a number of studies have confirmed that positive achievement emotions are positively associated with students' control and positive value appraisals, while the oppositepattern has generally been found for negative achievement emotions (Goetz et al., 2010; King and Gaerlan, 2014; Pekrunet a1., 2011). Moreover, the control-value framework postulates that the affective impact of the sociat environment on achievement emotions is mediated by control and value appraisals (Pekrun, 2006). Accordingly, it is assumed that features of the learning environment that provideinformation related to controllability and academic values are of crucial importance for students' emotions. Consistent with this assumption, recent research has shown that a elassroom envirenment conveying positive relationships, enjoyment and mastery goat 
orientation positively prediets students' academic self efficacy, engagement and achievement and negatively predicts their anxiety at both individual and classroom levels(Arens, Morin, and Watermann, 2015; Frenzel et al., 2009; Reyes et al., 2012). However, this research has focused exclusively on domain general emotions or students' math related emotions, and has neglected students' emotions in language learning.

In the present FL context, perceived peer emotions provide meaningful signalsreflecting their appraisats of the langurge learning events. They may influence students' emotions either directly as a result of emotion contagion (Hatfield et al., 1994) or by affecting students' control-value appraisals (Pekrun and Perry, 2014). Appraisal mediationwould be consistent with the social appraisal account of interpersonal emotional influence in which the integration of information gleaned from others' emotions into one's ownevaluation of an emotional situation plays an important role (Parkinson and Simons, 2009). Fo date, there is a lack of empirical evidence documenting the relationships between perceived peer emotions and students' ivedappraisals and emotions in learning in general and FL learning in particular.

\section{Methodological Considerations}

In the present study, data from 3643 participating students were nested within data from 103 classrooms and corresponding teachers. Therefore, testing our assumptions required a multilevel analysis approach. For perceived peer emotions, students were asked to directly fate the level 2 (L2) construct on items having the classroem as the referent, i.e. students- 
rated all their classmates' emotions as a whole in the FL classroem, thus providing at measure of shared emotional experience among all the students within the same class. The aggregated perceptions reflect the same underlying $L 2$ constructs or climate, and students' ratings within the same class are theoretically 'interchangeable' (Marshet al, 2012). Thus, it seems to be more appropriate to measure this variable at the classroom level. However, we consider that students' perception of peers' emotions is also an individual characteristic unique to the specific person (Arens et al., 2015). This part of level 1 (L1) residual variances reflects individual differences in perceptions of classroom emotions that are not accountedfor by the shared emotional experience at $\mathrm{L} 2$. From this perspective, it is best to model the proposed relationships between peer and student emotions at both individual and classroom levels.

For control-value appraisals and achievement emotions, students were asked to rate theE1 construct on items with the individual student as the referent. Here, the 12 classroom levels of these variables are based on the class-average aggregates of individual student L1 characteristics that are specific to each person, and not interchangeable with other studentsin the class (Morin et al., 2014; e.g., class average achievement, class average SES, student gender). Thus, these measures represent contextual variables similar to student achievement and self-concept as identified in the "big fish little pond effect" (BFLPE; see Marsh et al., 2008). That is, classroom average achievement and competence have a negative effect on students' academic self-concept after controlling for individual achievement. In this study, appraisals may have distinct effects on emotions at the individual student level and at theelassroem level. The relations between 12 elassroem levels of control value appraisals and 
student emotions represent a contextual effect and thus need to be properly estimated by controlling for the L1-effect when assessing the L2 effect (Morin et al., 2014). This can be done by calculating an additional parameter representing the difference between the $\mathrm{L} 2$ and t1 coefficients, providing a direct estimate of contextual effects (Enders and Tofighi, 2007), with the multivariate delta method (e.g., Raykov and Marcoulides, 2004). Similarly, theindirect effects of classroom level perceived peer FL emotions on student emotions asmediated by control value appraisals need to be caleulated while taking into accomt the contextual nature of the effects of control-value appraisals on emotions.

\section{Doubly Latent Multilevel Analysis}

It is very common in education and language research that the data have a hierarchical or nested structure (Cunnings, 2012; Marsh et al., 2009). For example, students are nested within the classrooms, and classrooms are nested within the schools. However, many traditionalpast classroom studies have suffered from two critical problems: (a) treating classroom constructs as a student-level (L1) variable in single-level analyses instead of a classroom-level (L2) variable in multilevel analyses that control sampling error in the aggregation of L1 ratings to form L2 constructs (e.g., Khajavy et al., 2016); and (b) relying on manifest-variable models rather than latent-variable models that control measurement error at $\mathrm{L} 1$ and $\mathrm{L} 2$, and sampling errer in the aggregation of $\mathrm{L} 1$ ratings to form $\mathrm{L} 2$ constructs (e.g., Delvaux et al., 2015). If researchers are interested in the effects of classroom variables, then the appropriate unit of analysis should be an L2 unit based on classroom-level constructs (climate, teacher, or peer). Evaluation of the effects of classroom variables based 
on L1 student-level constructs is a classic ecological fallacy (see Marsh et al., 2009), as the effects observed at the individual student level may differ from those at the classroom level. A vivid illustration of this ecological fallacy comes from classroom research on the big-fishlittle-pond effect (BFLPE; Marsh et al., 2008). This research shows that achievement at the individual-student level has a positive effect on academic self-concept, but school- or classroom-average achievement has a negative effect on academic self-concept. That is, the effect of a student's achievement on his/her academic self-concept depends on the average achievement of other students in the class or school.

Applying multilevel analysis into the research of FL classroom emotion transfer, it is very probable that the effects of perceived peer emotions on an individual student's achievement appraisals and corresponding emotions are related to the average emotions of other learners in the class. For example, an individual student studying in an FL class characterizedfeatured by high enjoyment and low anxiety and boredom is likely to have highermore perceived control and positive value toward language learning, which, in turn, have a positive influence on the student's own enjoyment and a negative influence on their ownhis/her anxiety and boredom. It should be noted, however, that class-average control and value, as often measured by self-competence (e.g., self-concept and self-efficacy) and personal relevance (e.g., attainment value and utility value) related constructs, may have negative contextual effects on a student's own enjoyment and positive contextual effects on theirhis/her own anxiety and boredom, similar to those identified in the BFLPE (Marsh et al., 2012; Pekrun et al., 2019).

Given the nested data structure and the latent variables used in this study, we employed 
$\underline{\text { a recent development in multilevel analysis, doubly-latent multilevel analysis, to address }}$

these issues. A doubly latent multilevel analysis is based on latent variables with several

indicator variables, rather than using single manifest variables. The latent variable scores are

then nested within multiple levels. This approach is a combination of multilevel modeling

and structural equation modeling (SEM). The advantage of doubly latent multilevel analysis

$\underline{\text { lies in controlling for sampling error by considering the nested structure of the data as }}$

different scores of individual students (Level 1) are indicators of a latent class (Level 2) and

controlling for measurement errors by including multiple indicators representing for the

latent constructs (Marsh et al., 2012).

\section{Hypotheses}

The research reviewed thus far suggests that there are positive links between perceived peer emotions and students' self-perceivedption of emotions in the FL classroom. However, there is a lack of large-scale quantitative evidence about this relationship. Furthermore, regarding emotional transmission from peers to individual students, it is plausible that control-value appraisals are mediators of the relationships between perceived peer emotions and students' corresponding emotions. However, research has yet to examine social appraisal as a possible mediating mechanism linking perceived peer emotions and students' self-perception of emotions toward FL learning.

Addressing these research deficits, the present study aimed to explore the relationships between perceived peer emotions, control-value appraisals and students' achievement 
emotions in language classes. In analyzing the data, we took into account the multilevel structure of the data by estimating these relations both at the classroom and at the student levels to properly disentangle individual versus classroom components. At the class level, we also considered the contextual nature of the effects of appraisals on emotions. In sum, we tested the following hypotheses (see Figure 1):

Hypothesis 1. Perceived peer FL enjoyment, anxiety and boredom will positively predict students' corresponding enjoyment, anxiety and boredom (emotion transfer).

Hypothesis 2. Perceived peer FL enjoyment will positively predict students' control-value appraisals and perceived peer FL anxiety and boredom will have a negative influence on them.

Hypothesis 3. The relationships between perceived peer FL enjoyment, anxiety and boredom and students' corresponding emotions will be mediated by control-value appraisals (social appraisal) but still remain significant after controlling for the influence of appraisals (emotion contagion).

\section{Method}

\section{Participants and Procedures}

The sample consisted of 3,643 students $(54 \%$ male; mean age $=12.85, S D=.89)$ in 103 seventh- to ninth grade classrooms from $6 \underline{\text { six }}$ middle schools in a city in Southeastern China. 
477 participants $(12 \%$ of the total 4120$)$ were excluded from the final sample due to serious missing data (more than 50\%). The reason for this level of such-missing data was that $\underline{\text { students were asked to answer the questionnaire during the ten--minutes class interval and }}$ $\underline{\text { some of them were unable to complete all items in thisa relatively short time given their }}$ young age. Among the six schools sampled, one was a school for migrant children from rural families, two were lower-middle level schools, the other two were upper-middle level schools, and one was an elite private school. Such a combination is representative of the current school structure in the city. As such, the students taking part came from a wide range of socio-economic backgrounds, including both rural and city registered children. The average number of students per class was 35.37 (Minimum $=21$, Maximum $=55, S D=$ 5.38). Students attended two English classes for 1.5 hours per day from Monday to Friday. Employing a teacher-centered approach, teachers were responsible for helping students acquire four basic fourskills (i.e., listening, speaking, reading and writing) in English and master the usage of a vocabulary list of 1500 to 2000 words in three years of study (People's Education, 2016).

Data were collected by trained research assistants during regular school days in the middle (early November) of the winter semester which typically begins in early September. At this point, students have definitely formed their perceptions of peers' emotions during English lessons and their appraisals and emotions about the subject. Moreover, all the instructions in this study asked students to report their class-related emotions and appraisals over the most recent two weeks so that these perceptions were more salient to them at the time of investigation. At the beginning of the survey, students were informed about the 
purpose and the voluntary nature of participating in this research, and told that they couldan withdraw from the survey any time during the data collection. Research assistants read aloud the instructions to students and were available to respond to any questions. Teachers were not present during data collection. Since one teacher taught at least two classes in the present sample, we randomly selected one class per teacher in order to avoid a possible three-level data structure. Students were informed about the general purpose of the research and its confidential nature. Written consent forms permitting students to participate in the study were obtained from the school principal.

\section{Measures}

Perceived peer emotions. Due to the lack of any existing questionnaire measuring perceived peer emotions, we developed a scale to assess students' perception of peers' enjoyment, anxiety and boredom in FL classes. We modified items from the class-related Achievement Emotion Questionnaire (AEQ; Pekrun et al., 2011) which contains eight emotion subscales and a total of 80 items. Specifically, eEach perceived peer emotion was measured by five items selected from the original scale. The selection criteria for all items assessing $\theta$ f the latent variables used in the present study were based on expert judgment, existing literature and consultation with authors' of the original scales (Marsh \& O’Neill, 1984; Pekrun et al., 2011). fFFollowing Marsh et al.'s (2012) recommendations, ${ }_{-2}$ we used a uniform stem "My classmates..." usedfor each item sentence-measuring perceived peer emotion (e.g. Enjoyment: "My classmates 
enjoy being in this English class.” Anxiety: "My classmates feel nervous in this English class." Boredom: "My classmates get bored in this English class."). In this way, the referent is the classroom (or classmates as a groupwhole) and individual students' ratings are interchangeable in relation to the classroom level of the variable in that every student is instructed to rate the same construct (Morin et al., 2014). Students reported the extent to which they agreed with each statement using a 5-point Likert scale $(1=$ strongly disagree; 5 = strongly agree), and the scores were summed to form the perceived emotion indices (enjoyment $\alpha=.88$, anxiety $\alpha=.82$, boredom $\alpha=.84$ ).

Control and value appraisals. Students' perceived control was measured by a shortversion of Marsh and O’Neill's (1984) Self-Description Questionnaire (SDQ), which originally included 42 items measuring students' academic self-concept in different facets (general, school, English and math). The SDQ has also been validated in a Chinese high--

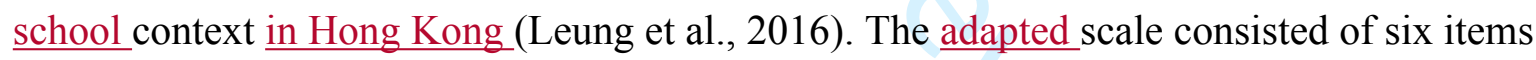
assessing students' self-concept concerning the subject of English (e.g. I have always done well in English). Participants responded to a 5-point scale $(1=$ strongly disagree to $5=$ strongly agree), and the internal consistency of the scale was high in the present study ( $\alpha$ $=.89$ ). Students' perceived lesson value was assessed using a six-item version of the Task Value Questionnaire (Pekrun and $\underline{\&}$ Meier, 2011). This scale measures students' intrinsic, utility and attainment value (two items for each dimension) related to English learning (e.g., "I find learning English is very interesting"; "I think learning English is very useful for me"; "It is important to me get good grades in this course". $1=$ strongly disagree, $5=$ strongly agree). Scores on the six items were summed to form the value index $(\alpha=.77)$. 
Achievement emotions. Students' achievement emotions were assessed using the above mentioned course-related emotion scales of the Achievement Emotion Questionnaire (Pekrun et al., 2011). By modifying the instruction of the original AEQ, the new measure provided a description of the English class related situation referred to in the assessment and then asked respondents to report how they felt when sitting in the language course. The scales assessed three emotions usingthat each contains five items for each emotion: enjoyment (5 items;e.g., "I enjoy participating in this English class so much that I get energized"), anxiety (5 items; e.g., "I get scared that I might say something wrong in this English class") and boredom (5 items; e.g., "I find this English class fairly dull"). Participants responded on a 1 (not at all) to 5 (very much) scale, and the scores were summed to form the emotion indices (enjoyment $\alpha=.85$, anxiety $\alpha=.80$, boredom $\alpha=.84$ ).

Covariates. At the student level, gender was included as a potentially confounding covariate because girls tend to report both more enjoyment and more anxiety in academic learning (Frenzel et al., 2007; Pekrun et al., 2011). At the classroom level, grade was included as a covariate because past research has demonstrated that this variable was negatively associated with students' perception of classroom environment (Morin et al., 2014). Moreover, students' previous English achievement was included as a covariate at both individual and class levels. Previous achievement has been shown to have significant effects on students' academic self-concept and achievement emotions (Marsh et al., 2009; Pekrun et al., 2014).

The final questionnaire containeds demographic questions and a total of 62 scale items. All scales used in the present investigation were translated from English to Chinese (see 
supplementary material). The English version of the questionnaire was used as the basis for translation by one educational psychologist and one bilingual English professor. The translations were then blindly back-translated by two bilingual $\mathrm{PhD}$ students in educational psychology. After this, both Chinese and English versions of the questionnaire were presented to a translation expert and another bilingual English professor, who further reviewed and polished the wording of the items to reach the closest possible equivalence across language versions. Finally, a pilot-test was also conducted on 104 students to check the wording and internal consistency of the new instrument. These participants were excluded from the final sample. All items and scales demonstrated good item-total correlation and reliability in the pilot-test.

\section{Data Analysis Strategy}

In the present study, data from 3,643 participating students were nested within data from 103 classrooms and corresponding teachers. Therefore, testing our assumptions required a $\underline{\text { multilevel analysis approach. For perceived peer emotions, students were asked to directly }}$ rate the level 2 (L2) construct on items having the classroom as the referent, i.e. students $\underline{\text { rated all their classmates' emotions as a whole in the FL classroom, thus providing a }}$ measure of shared emotional experience among all the students within the same class. The aggregated perceptions reflect the same underlying L2 constructs or climate, and students' ratings within the same class are theoretically 'interchangeable' (Marsh et al., 2012). Thus, it seemeds to be more appropriate to measure this variable at the classroom level. However, 
we consider that students' perception of peer emotions is also an individual characteristic unique to the specific person (Arens et al., 2015; Frenzel et al., 2018). This part of level 1 (L1) residual variances reflects individual differences in perceptions of classroom emotions that are not accounted for by the shared emotional experience at L2. From this perspective, it is best to model the proposed relationships between peer (i.e. perceptions of peers) and $\underline{\text { student (i.e. individual self-perception) emotions at both individual and classroom levels. }}$

For control-value appraisals and achievement emotions, students were asked to rate the $\underline{\mathrm{L} 1 \text { construct on items with the individual student as the referent. Here, the L2 classroom }}$ levels of these variables are based on the class-average aggregates of individual student L1 $\underline{\text { characteristics that are specific to each person, and not interchangeable with other students }}$ in the class (Morin et al., 2014; e.g., class-average achievement, class-average SES, student gender). Thus, these measures represent contextual variables similar to student achievement and self-concept as in the above mentioned BFLPE (Marsh et al., 2008). This raises the possibilityindicates that class-average control and value appraisals may have a negative $\underline{\text { effect on students' enjoyment but a positive effect on their anxiety and boredom after }}$ controlling for individual level of control and value. This contextual effect needs to be properly estimated by calculating an additional parameter representing the difference between the L2 and L1 coefficients, providing a direct estimate of contextual effects (Enders

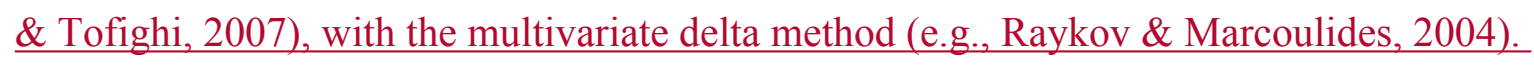
$\underline{\text { Similarly, the indirect effects of classroom level perceived peer FL emotions on student }}$ corresponding emotions as mediated by control-value appraisals need to be calculated while taking into account the contextual nature of the effects of control-value appraisals on 
emotions.

In the past, many traditional classrom studies have suffered from critieal problems:(a) treating clas өf a Fariable models rather than latent wariable models that control measurement error at 11 and E2, and sampling error in the agoregation of $\mathrm{L} 1$ ratings to form $\mathrm{L} 2$ construets (e.g. Delvalu et al.2015):Fo overcome these problems and keep pace with recent developments in multilevel analyses, we used-

Mplus 8.0 (Muthén and_\& Muthén, 1998-2017) was used to construct our doubly-latent multilevel structural equation models (ML-SEM). The ML-SEM approach has the advantage of taking into account measurement error and sampling error at both levels and testing the hypothesized direct and indirect effects simultaneously at each level while controlling for the influence of the other (Marsh et al., 2009). Moreover, employing this method, the validity and reliability of the measures can also be assessed across the two levels (Morin et al., 2014). In addition, we relied on the full information maximum likelihood (FIML) method implemented in Mplus, rather than a quasi-listwise deletion strategy, to handle missing data (Enders, 2010). FIML, especially when used in conjunction with robust Maximum Likelihood (MLR) estimator, has been found to result in unbiased parameter estimates under even very high levels of missing data, and thus better represents the entire sample, rather than just the subsample of students who have no missing data. MLR has been found to be efficient in the estimation of latent-variable models based on either normally or non-normally distributed responses and items rated on scales including five or more 
response categories (Muthén $\underline{\&}$ Muthén, 1998-2017).

\section{Preliminary Verification of Statistical Requirements}

In doubly latent multilevel models, in addition to multicollinearity at level 1 and level 2, the reliability of the class aggregates, and of the constructs at L1 and L2, together with the verification that the a priori measurement model fits the data well at both levels are important statistical requirements that should routinely be checked. First, in order to facilitate interpretation of the results and to reduce non-essential multicollinearity, all variables were standardized before analysis, and variables used only at L1 were grand mean centered whereas variables modelled at both levels were group mean centered (Marsh et al., 2009). We also directly performed systematic tests which showed that both Tolerance $(>1)$ and VIF $(<2)$ values remained reasonably low. Thus, there were no potential problems of multicollinearity in individual ratings of the constructs used in the present investigation.

Next, to determine whether aggregated individual-level ratings of students' emotions, appraisals and perceived peer emotions were reliable indicators of the respective class-level constructs, we used the intraclass correlation coefficient Type 1 and 2 (Bliese, 2000). ICC1 refers to the agreement between any pair of students within the same class and also reflects the proportion of the total variance that occurs at the second level of analysis. ICC1 thus provides an estimate of the within-class homogeneity of aggregated group-level constructs. Values of .05 or above for ICC1 can be regarded as evidence that there are adequate grouplevel properties of a variable to warrant aggregation (Gavin and Hofmann, 2002). 
Whereas ICC1 can be interpreted as the reliability of an individual student's rating as an indicator of a class-level variable, ICC2 provides an estimate of the reliability of the classmean or class--aggregated average rating (Lüdtke et al., 2006). ICC2 values of approximately .70 are considered to indicate sufficient reliability of class-level aggregated scores (Marsh et al., 2012). These indices were satisfactory in this study and thus justified the assessment of all the variables at class level: enjoyment $(\mathrm{ICC} 1=.12, \mathrm{ICC} 2=.082)$, anxiety $(\mathrm{ICC} 1=.09, \mathrm{ICC} 2=.78)$, boredom $(\mathrm{ICC} 1=.17, \mathrm{ICC} 2=.88)$, perceived control $(\mathrm{ICC} 1=.08, \mathrm{ICC} 2=.76)$, perceived value $(\mathrm{ICC} 1=.15, \mathrm{ICC} 2=.86)$, perceived peer enjoyment $(\mathrm{ICC} 1=.13, \mathrm{ICC} 2=.84)$, perceived peer anxiety $(\mathrm{ICC} 1=.09, \mathrm{ICC} 2=.77)$, perceived peer boredom $(\mathrm{ICC} 1=.16, \mathrm{ICC} 2=.87)$.

Further, following Marsh et al.'s (2012) recommendation, we conducted multilevel confirmatory factor analyses (ML-CFA) for all thesix structural models tested in the study to check whether the a priori factor model holds at both L1 and L2. Traditional cutoff criteria indicative respectively of excellent and adequate fit to the data were used (Byrne, 2011): (i) CFI (comparative fit index) and TLI (Tucker-Lewis index) $\geq .95$ and $\geq .90$; (ii) RMSEA (root mean square error of approximation) $\leq .06$ and $\leq .08$. Model fit indices demonstrated that they provided very good fit to the data (see Table 3).: enjoyment (peer, student) and appraisal (control/value) model $(\mathrm{CFI}=.96 / 97, \mathrm{TLI}=.96 / .96$, and RMSEA $=.26 / .25)$, anxiety (peer, student) and appraisal (control/value) model (CFI - 97/97, TLI - 97/.96, and RMSEA = .24/.26), boredom (peer, student) and appraisal (control/value) model (CFI $=.96 / 96, \mathrm{TLI}=.95 / .95$, and RMSEA $=.26 / .26)$.

Finally, based on parameters obtained from the above ML-CFA models, we computed 
McDonald's (1970) omega ( $\omega)$ to estimate the reliability of different latent constructs at level 1 and level 2. Compared with traditional scale score reliability estimates (e.g., alpha), $\omega$ has the advantage of taking into account the strength of association between items and constructs as well as item-specific measurement errors and to be applicable to the estimates obtained at both L1 and L2 based on level-specific variance-covariance matrices (Morin et al., 2014). $\Omega$ coefficients are interpreted as any other composite reliability coefficients (above .70 indicates sufficient). These indices were fully satisfactory for enjoyment $(\omega=$ $.84 / .92$ at $\mathrm{L} 1 / \mathrm{L} 2)$, anxiety $(\omega=.79 / .93)$, boredom $(\omega=.80 / .96)$, perceived control $(\omega=$ $.88 / .97)$, perceived value $(\omega=.75 / .96)$, perceived peer enjoyment $(\omega=.86 / .98)$, perceived peer anxiety $(\omega=.83 / .95)$ and perceived peer boredom $(\omega=.81 / .96)$. It should be noted that these coefficients operated independently at L1 and L2, and the reliability were substantially higher at L2. In other words, when estimating L2 constructs, doubly latent models partialed out the unreliability of agreement between students forming each class and the classaggregated ratings of these latent variables were more reliable than individual ratings (Marsh et al., 2012).

\section{Results}

\section{Preliminary Analyses}

Table 1 displays the descriptive statistics for each of the variables in the study. The scores on all variables except for previous English achievement (negatively skewed) were normally 
distributed and there were sufficient variations within each variable as indexed by their standard deviation and range. Students generally experienced more enjoyment than anxiety or boredom in their English class. Multiple group mean comparison showed that the differences between each pair of the three emotions were significant, $[F(2,10-917)=$ 2348.86, $p<\theta . \underline{0} 01\}$. Similar differences also applied when comparing students' perceptions of peer enjoyment, anxiety and boredom ${ }_{2}[F(2,10,885)=2581.71, p<\theta . \underline{0} 01\}$. Moreover, students tended to assign a relatively high value to learning English but reported only a moderate level of control over their learning of this subject ${ }_{2}(t[1,(7277])=34.93, p<.001)$.

Table 2 presents the Pearson product-moment correlations between study variables at both individual and classroom levels. Students' FL enjoyment, anxiety and boredom were positively linked with corresponding perceptions of peer enjoyment, anxiety and boredom. Both control appraisal and value appraisal were positively related to student and perceived peer enjoyment, but were negatively related to student and perceived peer anxiety and boredom in language classrooms. Student and perceived peer FL enjoyment were negatively related to student and perceived peer anxiety and boredom. All the directions of correlations were the same and ranged from moderate to strong across the two levels. These correlations provide preliminary evidence for the hypothesized relationships between perceived peer emotions, appraisals and student emotions. The results also confirm the appropriateness of the included control variables, which were significantly (weakly for gender and performance but moderately for grade) related to perceived peer FL emotions, control-value appraisals and student emotions.

ML-SEM Analyses 
To test Hypothesis 1 that perceived peer FL enjoyment, anxiety and boredom would be positive predictors of students' corresponding enjoyment, anxiety and boredom, we regressed student emotions on corresponding perceived peer emotions at the individual level and at the classroom level in three separate models (i.e., perceived peer emotion was the independent variable and their corresponding student emotion was the dependent variable in

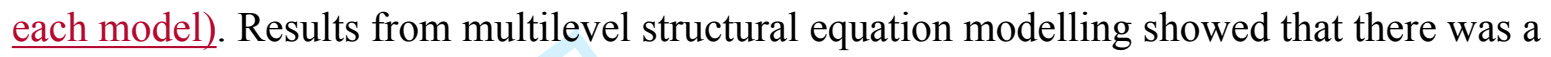
significant positive main effect of perceived peer FL enjoyment on student enjoyment at both individual $(\beta=.68, p<. \underline{001})$ and class levels $(\beta=.73, p<. \underline{001})$ after controlling for all covariates. Similarly, perceived peer FL anxiety was a significant positive predictor of student anxiety (individual/classroom; $\beta=.65, p<\underline{.001 / \beta}=.71, p<. \underline{001})$ and perceived peer FL boredom was a significant positive predictor of student boredom (individual/classroom; $\beta=.64, p<. \underline{001 /} \beta=.44, p<. \underline{001}$ ) across the two levels. Thus, all measured peer emotions were positively associated with the corresponding student emotions, as predicted.

In a next step, we separately added perceived control and perceived value to both the individual and the classroom levels of each model to test the associations between perceived peer emotions and control-value appraisals (Hypothesis 2). At the individual student level, perceived peer FL enjoyment positively predicted control appraisals $(\beta=.45, p<. \underline{001})$ and value appraisals $(\beta=.55, p<. \underline{001})$. By contrast, perceived peer FL anxiety and boredom negatively predicted both appraisals of control (anxiety/boredom; $\beta=-.40, p<. \underline{001} / \beta=-.28$, $p<. \underline{001}$ ) and value (anxiety/boredom; $\beta=-.25, p<. \underline{001} / \beta=-.45, p<. \underline{001}$ ). There were also 
corresponding effects at the classroom level. Perceived peer FL enjoyment was again a significant positive predictor of control appraisal $(\beta=.50, p<. \underline{001})$ and value appraisal $(\beta$ $=.66, p<.001)$, and perceived peer FL anxiety and boredom were again both significant negative predictors of control (anxiety/boredom; $\beta=-.41, p<. \underline{00} 1 / \beta=-.53, p<. \underline{001}$ ) and value (anxiety/boredom; $\beta=-.27, p \leq \underline{=} .05 \underline{4} / \beta=-.46, p<. \underline{001})$ appraisals. Thus, peer emotions influenced student appraisals at both levels as predicted.

In the third step, we explored the relationship between perceived peer emotions and students' corresponding emotions in more detail by testing Hypothesis 3, which predicted that this relationship should be mediated by control and value appraisals but remain significant after controlling for these mediators. Each student emotion was regressed on control appraisal and value appraisal separately in the above six models. The goodness of fit indices for the final six ML-SEM models are reported in Table 3. As can be seen, the inspected range of fit indices demonstrate that these models have a good fit to the data. Finally, Table 4 presents all the unstandardized and standardized path coefficients obtained from these final models.

At the individual level, control appraisal had a significant positive effect on student FL enjoyment but a significant negative effect on student FL anxiety and boredom when controlling for corresponding perceptions of peer enjoyment, anxiety and boredom. Moreover, the influences of perceived peer FL enjoyment, anxiety and boredom on students' corresponding enjoyment, anxiety and boredom were reduced but still significant when control appraisal was added to each model as another predictor of students' emotions.

Mediation analyses further confirmed that the indirect effects of perceived peer 
emotions on students' corresponding emotions through control appraisal were significant for FL enjoyment (Sobel's $z=3.64 \underline{\beta=.16}, p<. \underline{001})$, anxiety $(z=4.41 \underline{\beta=.12}, p<. \underline{001})$ and boredom $(z=5.08 \underline{\beta=.06}, p<. \underline{001})$. Similarly, value appraisal was a significant positive predictor of student FL enjoyment but a significant negative predictor of student FL anxiety and boredom after controlling for corresponding perceived peer emotions. The effects of perceived peer FL enjoyment, anxiety and boredom on students' corresponding enjoyment, anxiety and boredom remained significant after controlling for the influence of value appraisal. The mediating effects of value appraisal in the relationship between perceived peer emotions and corresponding students' emotions were significant for FL enjoyment ( $z=$ $3.55 \underline{\beta=.22}, p<. \underline{001})$, anxiety $(z \underline{\beta}=z . \underline{0477}, p \leq=.0 \underline{04} 4)$ and boredom $(\underline{\beta z}=4 . \underline{18} 59, p$ $<.001)$.

At the classroom level, the effects of control appraisal on students' emotions were reduced to nonsignificant for FL enjoyment and boredom but became significantly positive for FL anxiety when taking account of the contextual nature of this relationship and controlling for the influence of corresponding perceived peer emotions. The effects of perceived peer FL enjoyment, anxiety and boredom on students' corresponding enjoyment, anxiety and boredom were diminished but still significant after controlling for control appraisal. The only possible mediation effects of control in the relationship between perceived peer FL anxiety and student anxiety were significant ( $\underline{\beta z}=-z .0 \underline{13} F, p=\leqslant .05 \underline{27})$. On the other hand, value appraisal was no longer a significant predictor of FL enjoyment and anxiety but became a significant positive predictor of FL boredom when taking into account the contextual effects and controlling for corresponding perceived peer emotions. 
The influences of perceived peer FL enjoyment, anxiety and boredom on students' corresponding enjoyment, anxiety and boredom were lessened but remained significant after controlling for value appraisal. Mediation analyses showed that the indirect effects of perceived peer FL boredom on student boredom through value appraisal were significant ( $¥ \underline{\beta}$ $=-2 . \underline{24}, p \leq=.015)$.

\section{Discussion}

The present study showed that students' perceptions of peer enjoyment, anxiety and boredom were positively linked with their own enjoyment, anxiety and boredom in language classes, even when controlling for students' gender, grade, and previous English achievement. This is in line with social-cognitive learning theory's (Bandura, 1977; Pekrun, 2006) assumption that the ongoing social interactions between peers and students in the classroom are likely to influence students' cognition, emotions and behaviors. It also supports an overall emotion transfer from peers to students in the FL classroom (Elfenbein, Cao, 20142014). Moreover, this relationship was found to be robust across student and class levels. This confirms the appropriateness of treating perceived peer emotions as classroom climate constructs as well as individual specific characteristics.

Consistent with our hypotheses, we found that control and value appraisals partially mediated the relationships between perceived peer FL enjoyment, anxiety and boredom and students' corresponding emotions. However, due to the contextual effects of appraisals on achievement emotions, control-value appraisals had differential effects on students' FL 
enjoyment, anxiety and boredom at the individual level and at the classroom level.

Specifically, at the personal level, both control and value appraisals had positive effects on students' FL enjoyment but negative impacts on students' FL anxiety and boredom. The partial mediating effects of either control appraisal or value appraisal in the relationships between perceived peer emotions and students' corresponding emotions were all positively significant. This is in line with both the emotion contagion and the social appraisal accounts

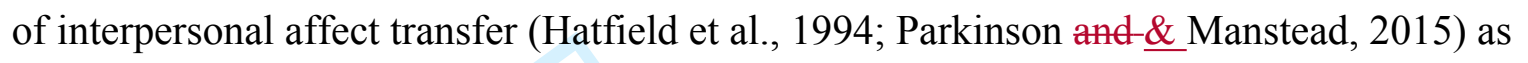
well as the mediation assumption posited by the control-value theory of achievement emotion (Pekrun, 2006; Pekrun and $\underline{\&}$ Perry, 2014).

When a student senses his/her peers' FL emotions on an individual basis, higher perceived peer enjoyment and lower perceived peer anxiety and boredom have positive influences on the student's control and value appraisals, which in turn result in higher levels of student enjoyment and lower levels of student anxiety and boredom (Shao et al., 2020a). Perceived peer FL enjoyment, anxiety and boredom may also be directly contagious to students' corresponding emotions without the influences of perceived control and value. These perceptions of language appraisals and emotions represent individual characteristics unique to each student independent of the shared classroom level effects (Morin et al., 2014).

At the classroom level, control appraisals had positive effects on students' FL anxiety and value appraisals had positive effects on students' FL boredom. The class-level positive effects of appraisals on FL emotions can be explained by the afore-mentioned "big-fishlittle-pond effect" (Marsh et al., 2008), which has also been replicated in many emotion 
studies demonstrating that class-average achievement can have negative contextual effects on students' enjoyment and positive contextual effects on their anxiety and boredom by educational psychologists (Arens et al., 2015; Frenzel et al., 2007 Pekrun et al., 2019). Although the present study measured students' self-reported competence, research has shown that students' academic self-concept tends to have high correlations with their actual performance (see Möller et al., 2020 for a meta-analysis). This indicates that the higher the perceived class's perceived average competence inever the English languagesubject was, the higher the students' anxiety toward language learning was. Similarly, the higher the perceived class's perceived average valuation ofe toward the English language was, the higher students' boredom was in relation tofor the learning activity.

One explanation for these findings may be that they reflect the current middle school education in China, which overemphasizes the competitiveness and the attainment value of high-stake English exams. Students studying in high FL competence classes are surrounded by peers who have high-mean ability and scores in English, which results in relatively low individual self-confidence for English learning (Marsh et al., 2012). This may lead individual students to tose intrinsic motivation and-feel nervous and bored about English study. High class-average competence and value may also correspond to higher achievement demands in the respective class and probably also to higher pacing (Frenzel et al., 2007), which in turn seems to positively influence students' experience of anxiety and boredom when learningef English in that class. This seems to be also supported by the nearsignificant positive effects of the class's mean score of value for students' FL anxiety. Importantly, the present study extends previous findings by showing that the emotion 
contagion and social appraisal processes may operate not only at the individual level but also at the collective level (Borg, 2006; Delvaux et al., 2015Parkinson, 2019). It also contributes to existing literature by demonstrating that control and value appraisals had the oppositereverse effects on students' FL emotions at the class level to as compared with those operating at the individual level.

Overall, our data demonstrated that perceived peer FL enjoyment had positive influences on students' control and value appraisals and on own enjoyment at individual and class levels while the opposite trend was observed for perceived peer FL anxiety and boredom. This implies that peers do make a difference to students' emotional experiences in the language classroom and may also affect howstudents' FL emotions change across time_ cognitive appraisals off the-FL tasks (Khajavy et al., 2018; Shao et al., 2019). Moreover, the significant mediated effects of perceived peer emotions on students' corresponding emotions through appraisals add to the literature on peer-and stent_affect transfer and provide evidence regarding potential underlying processes in FL classrooms (Delvaux et al, 2015). Specifically, peer FL emotions may impact students' self-perception of emotions either directly through automatic contagion (Moskowitz \& Dewaele, 2019Hatfieldet al., 1994) or indirectly through influencing their control and value appraisals (Parkinson and $\underline{\&}$ Manstead, 2015;__Pekrun, 2006 Shao et al., 2019), which in turn lead to different levels of languagerelated emotional experiences.

\section{Changing Students' Language Outcomes by Changing the Collective Peer Emotions}

\section{Practical Applications of Research Findings}


Students' FL emotions and performance are often attributed to personal factors such aslearning strategies, motivation, appraisals, and goal orientations (Bown andWhite, 2010; Satio et al., 2018). Although language related emotions and achievement can be attributed to a great extent to individual student differences, more and more FL researchers attributestudent emotions and academic performance at least in part to aspects of the classroom envirenment stch as student teacher relationship, peer support and classroem climate(Khajavy et al., 2018; Peng andWoodrow, 2010). The findings from the current study demonstrated that positive peer emotions have the potential to improve students' controlvalue appraisals and emotions at the level of the FL classroom as a whole, thus resulting in improvements for individual students within each classroom. This suggests that student FL interventions might profitably target the emotional climate of the whole class._-For example, FL teachers can create a positive emotional atmosphere for language learning by demonstrating that the classroom is a valuable place to be and by beingare enthusiastic about acquiring the target language ( $\mathrm{Shao}, \mathrm{Yu}_{2}$ and $\underline{\&} \mathrm{Ji}, 2012$ ). Teachers should not only be effective at helping students solve problems in FL learning but also be highly aware of, and responsive to, students' social and emotional needs in the language acquisition process. If teachers notice signs of students' signs of anxiety in the FL classrooms, they may adjust their instructional strategies bystch as showing a sense of caring for students' negative feelings, providing delayed error correction, and emphasizing enthe positive value of making mistakes in language acquisition, so that students can feel comfortable usingto use

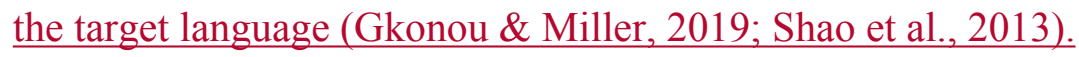


Moreover, one of the key considerations infacters for building a positive classroom environment is that teachers make language learning an enjoyable rather than boring experience for students. Teachers can design interesting and challenging language tasks that allow students to develop a sense of autonomy and experience flow whileduring filling the knowledge gap (Dewaele et al., 2019). It is also advised that teachers incorporate more $\underline{\text { innovative and stimulating teaching techniques into the language curriculum (e.g., }}$ technology-based learning, movies, role play, participating in fictional talk shows or live interviews etc; Hwang et al., 2017; Shao et al., 2019). For example, teachers may select different types of background music to match teaching content, students' preferences and learning contexts. The fine-tuned music may hit the emotional sweet spot of language learners thatwhich facilitates their language learning and engagement (Kang \& Williamson, 2014).

Furthermore, FL teachers can nurture positive peer emotions by promoting cooperative learning in and out of the classroom using cognitive scaffolding strategies such as requesting.

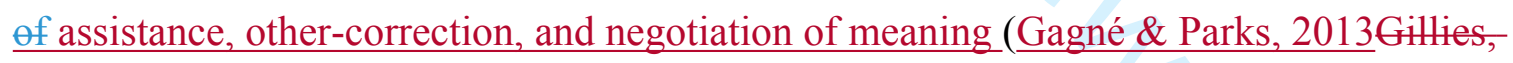
2004). When students work together toward the same learning goals, they start to build mutual support and shared responsibility with peers, and eventually develop a form of positive interdependence in which the language success of one student depends upon the success of all other students (Johnson $\underline{\&}$ Johnson, 2009). Such a language classroom is characterized by a sense of connectedness and belongingness, enjoyment and enthusiasm, and respect (Reyes et al., 2012). As a result, students feel more cheerful and competent in FL learning, and become more successful language learners. 
Chinese EFL teachers (see above discussion), in particular, can adopt a mastery goat orientation in the classroom despite the competitive nature of high-stake exams. On the onehand, this can reduce the tensions associated with competition between peers and offset the negative impact of norm referenced exams in which only a few students can excel academically. On the other hand, a mastery classroom environment is conducive to the formation of intrinsic motivation and positive peer relationships and has been shown to bepositively predictive of students' academic self efficacy, engagement and achievement at the elassroom and individual levels (Arens et al., 2015; Morin et al., 2014).

Finally, another way to achieve a positive classroom climate is forthat teachers toean openly express their personal enjoyment of language learning and teaching to their students. $\underline{\text { Research has demonstrated that teachers' expressed positive emotions such as enjoyment of }}$ $\underline{\text { teaching can significantly influence students' enjoyment of learning through emotional }}$ contagion (Frenzel et al., 2018; Moskowitz \& Dewaele, 2019). Thus, FL teachers are advised to be aware of their own emotions in class, up-regulate their pleasant emotions, and adopt an enthusiastic teaching style in order to create positive emotion interactions with $\underline{\text { students in language classrooms (Frenzel et al., 2018). Teachers' active cultivation of a }}$ $\underline{\text { sense of humor, friendliness and empathy are likely to generate more positive emotions for }}$ $\underline{\text { them and help students become happy, confident and proud language learners (Shao et al., }}$ 2013).

Another way to achieve a positive classroom climate is through teachers' activeeultivation of a sense of humor and a friendly and cooperative environment that can encourage students to collaboratively take risks in speaking the language (Dewaele et al., 


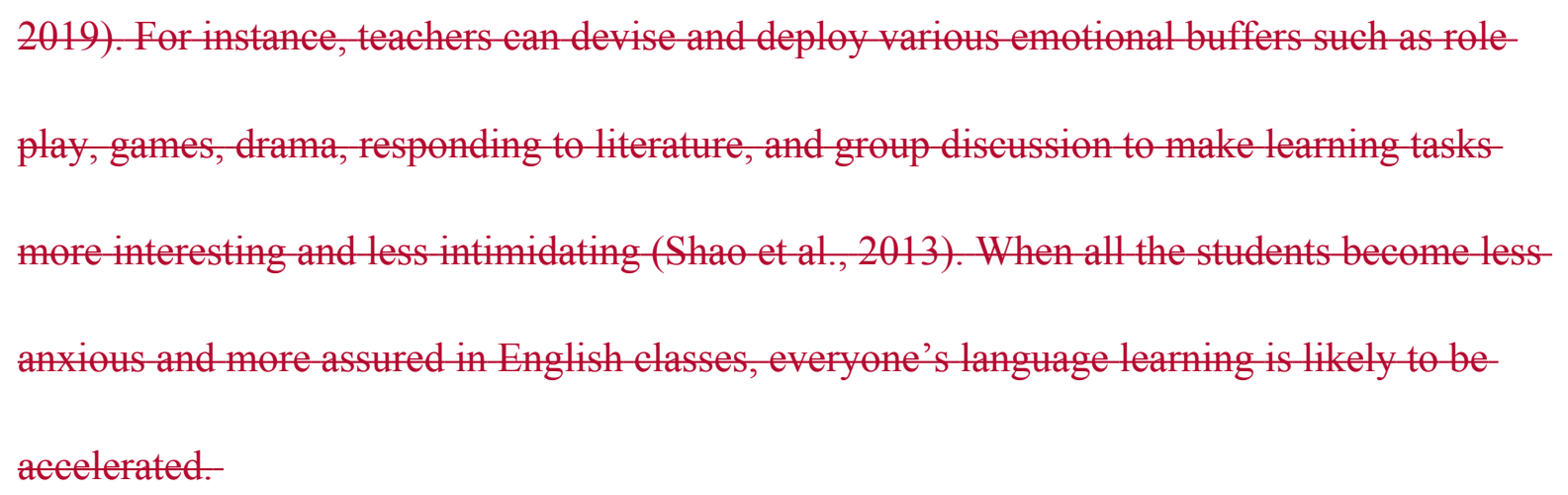

Some limitations of the present study may be used to suggest directions for future research. First, the use of cross-sectional data in the present study can only provide a snapshot of the highly dynamic emotional experiences during the FL learning process. $\underline{\text { Students may have verymuch different feelings at certain times of the academic semester, }}$ especially at the start, middle, and end of a term. Future research could include a longitudinal approach such as the latent growth curve model that could compare results of questionnaires from two or three different time points (Shirvan \& Taherian, 2018). predictive design of peer emotions on students' appraisals and emotions we used in the present EFL context is also limited due to the synchronous assessment of the study variables at one time point. While the proposed effects of peer FL emotions on students' control-value appraisals and corresponding emotions are theoretically plausible and supported by the current data, the reverse order of effects is also conceivable. This may in a sense also be supported by the present findings since every student is a peer of all other students. Thus, it would be interesting for future research to use repeated measures to address potential 
reciprocal effects between peer FL emotions, student appraisals and emotions (Delvaux et al., 2015; Pekrun et al., 2014).

Second, as all the variables in the present study were assessed by self-reported questionnaire which are susceptible to response bias, the predictive effects found in the present FL setting may be inflated by common method variance (Donaldson et al., 2000). Although self-ratings have the unique advantage of accessing internal feelings and thoughts, the subjective nature of these measures is often difficult to control. Future research should also include objective measures such as implicit measures of emotions, EEG or fMRI to assess appraisals and emotions. For instance, researchers may use video observation to record students' emotions in the FL classes and match the transcribed data with other instruments to analyze the proposed hypotheses (Reyes et al., 2012). Researchers may also ask teachers or parents to report students' language appraisals and emotions as an alternative approach to assessment.

Third, the present study used a rather molar approach for assessing relationships between peer and student emotions, which were both assessed in a trait-like manner with regards to a year-long English class. A trait-like assessment is meaningful as it captures the overall emotional tone in classrooms. However, it cannot embrace micro-processes that likely are at work in interpersonal transmission of emotions. Studies using a more finegrained experience sampling approach addressing appraisals and emotions in a specific lesson or a period of time (e.g. before an FL exam) could be designed to further explore the underlying emotion contagion and social appraisal processes in the transfer of affect between peer and students in FL classrooms (see Goetz et al., 2010). 
Fourth, the task value scale used to measure perceived value in the present research contains only two items for each dimension (intrinsic value, attainment value and utility value; Pekrun \& Meier, 2011) which makes it unfeasible to form latent variables for each value subscale (Muthén \& Muthén, 1998; -2017). Conceptually, these three dimensions represents different facets of value that have moderately strong correlations with one another (Putwain et al., 2018). For example, a student who likes reading English texts may not necessarily consider it important to get a good grade in the English exam. Therefore, it may be important that future research uses more items to measure each value dimension in order to acquire a more nuanced understanding ofn the relations between different facets of value appraisal and discrete emotions in FL classrooms.present research foused only on English as a foreign language in its analysis of students' emotions associated with language learning more generally. Since English is a required subject at all levels of education in China, students have no choice but to learn it as a foreign langurge and attach high attainment walue to the language. This may limit our understanding of the nature of emotions in FL learning. Students' emotional experiences may differ markedly under intrinsic vs. instrumental FL learning environments (Noels et al., 2000). Therefore, futmre replication studies could measure students' emotions in a non-mandatory language context (e.g, the optional second FL course for Chinese college students) to see whether the present findings hold, or whether there are moderation effects between different contexts.

\section{Conclusion}


The findings of the present study indicate that perceptions of peer emotions and students' self-perceivedption of emotions are closely linked by ways of emotion contagion and social appraisal in English classrooms. Insights into such processes underlying affective interaction between peers and individual students are of crucial importance since emotionally positive FL classrooms are likely to also be successful language classrooms. We have shown that when an FL classroom is characterized by highermore perceived peer enjoyment and loweress anxiety and boredom, students feel more in control and appreciate more of the learning subject, which should result in more positive affective experiences during language learningbetter language engagement and performance (Shao et al., 2019). This suggests that FL success is at least partly contingent upon the emotional components of the language learning environment. Thus, enhancing pleasant emotions and moderating unpleasant emotions at the classroom level should be an important goal of instruction for FL teachers and educators. FL classrooms filled with enjoyment of learning likely provide optimal contexts for meeting acquisition challenges and promoting language development and achievement.

\section{References}

Arens, A.K., Morin, A.J.S., and $\underline{\&}$ Watermann, R. (2015). Relations between classroom disciplinary problems and student motivation: Achievement as a potential mediator? Learning and Instruction, 39, 184-193.

Bandura, A. (1977). Social learning theory. Englewood Cliffs, NJ: Prentice Hall. 


\section{System, 38, $432 \quad 443$.}

Bliese, P. D. (2000). Within-group agreement, non-independence, and reliability: Implications for data aggregation and analysis. In K. J. Klein and S. W. Kozlowski (Eds.), Multilevel theory, research, and methods in organizations (pp. 349-381). San Francisco, CA: JosseyBass.

Borg, S. (2006). The distinctive characteristics of foreign language teachers. Language Teaching Research, 10,3-31.

Byrne, B.M. (2011). Structural equation modeling with Mplus: Basic concepts, applications, and programming. New York: Routledge/Taylor \& Francis.

Cao, Y. (2014). A socio-cognitive perspective on second language classroom willingness to communicate. TESOL Quarterly, 48, 789-814.

Cunnings, I. (2012). An overview of mixed-effects statistical models for second language researchers. Second Language Research, 28, 369-382.

Delvaux, E., Vanbeselaere, N., \& Mesquita, B. (2015). Dynamic Interplay Between Norms and Experiences of Anger and Gratitude in Groups. Small Group Research, 46, 300-323.

Dewaele, J.-M., \& MacIntyre, P.D. (2014). The two faces of Janus? Anxiety and enjoyment in the foreign language classroom. Studies in Second Language Learning and Teaching, 4, 237-274.

Dewaele, J.-M., Witney, J., Saito, K., \& Dewaele, L. (2018). Foreign language enjoyment and anxiety: The effect of teacher and learner variables. Language Teaching Research, 22, 676697.

Dewaele, J.-M., Magdalena, A. F., and $\underline{\&}$ Saito, K. (2019). The effect of perception of teacher 
characteristics on Spanish EFL learners' anxiety and enjoyment. The Modern Language Journal, 103, 412-427.

Donaldson, S. I., Thomas, C. W., Graham, J. W., Au, J. G., and $\underline{\&}$ Hansen, W. B. (2000). Verifying drug abuse prevention program effects using reciprocal best friend reports. Journal of Behavioral Medicine, 23, 585-601.

Elfenbein, H. A. (2014). The many faces of emotion contagion: An affective process theory of affective linkage. Organizational Psychology Rew, 4, 137.

Enders, C. K. (2010). Applied missing data analysis. New York, NY: Guilford Press.

Enders, C. K., \& Tofighi, D. (2007). Centering predictor variables in cross-sectional multilevel models: A new look at an old issue. Psychological Methods, 12, 121-138.

Fischer, A. H., Rotteveel, M., Evers, C., \& Manstead, A. S. R. (2004). Emotional assimilation: How we are influenced by others' emotions. Cahiers de Psychologie Cognitive, 22, $223-$ 245.

Frenzel, A. C., Becker-Kurz, B., Pekrun, R., Goetz, T., \& Lüdtke, O. (2018). Emotion $\underline{\text { transmission in the classroom revisited: A reciprocal effects model of teacher and student }}$ enjoyment. Journal of Educational Psychology, 110, 628-639.

Frenzel, A. C., Thrash, T., Pekrun, R., \& Goetz, T. (2007). Perceived learning environment and students' emotional experiences: a multilevel analysis of mathematics classrooms. Learning and Instruction, 17, 478-493

Frenzel, A.C., Goetz, T., Lüdtke, O., Pekrun, R., and Sutton, R. E. (2009). Emotional transmission in the classroom: Exploring the relationship between teacher and student enjoyment. Jouthal of Educational Psychology, 101, 705 716. 
Gagné, N., \& Parks, S. (2013). Cooperative learning tasks in a Grade 6 intensive ESL class: Role of scaffolding. Language Teaching Research, 17, 188-209.

Gavin, M. B., \& Hofmann, D. A. (2002). Using hierarchical linear modeling to investigate the moderating influence of leadership climate. The Leadership Quarterly, 13, 15-33.

Gillies, R.M. (2004). The effects of cooperative learning on junior high school studentsduring small group learning. Learning and Instruction, 14, 197 213.

Gkonou, C., \& Miller, E. R. (2019). Caring and emotional labour: Language teachers' engagement with anxious learners in private language school classrooms. Language Teaching Research, 23, 372-387.

Goetz, T., Frenzel, A.C., Stoeger, H., and \& Hall, N. C. (2010). Antecedents of everyday positive emotions: An experience sampling analysis. Motivation and Emotion, 34, 49-62.

Hatfield, E., Cacioppo, J. T., and쓰 Rapson, R. L. (1994). Emotional contagion. New York: Cambridge University Press.

Horwitz, E. K. (1996). Even teachers get the blues: Recognizing and alleviating language teachers' feelings of foreign language anxiety. Foreign Language Annals, 29, 365-372.

Johnson, D.W., \& Johnson, R.T. (2009). An educational psychology success story: Social interdependence theory and cooperative learning. Educational Researcher, 38, 365-379

$\underline{\text { Kang, H. J., \& Williamson, V. J. (2014). Background music can aid second language }}$ learning. Psychology of Music, 42(5), 728-747.

King, R. B., and Gaerlan, M. J. M. (2014). High self-control predicts more positiveemotions, better engagement, and higher achievement in school. European Journal of Edutent Psychology, 29,81 100. 
Khajavy, G. H., Ghonsooly, B., Hosseini, A., \& Choi, C. W. (2016). Willingness to communicate in English: A microsystem model in the Iranian EFL Classroom Context. TESOL Quarterly, 50, 154-180.

Khajavy, G. H., MacIntyre, P., \& Barabadi, E. (2018). Role of the emotions and classroom environment in willingness to communicate: Applying doubly latent multilevel analysis in second language acquisition research. Studies in Second Language Acquisition, 40, 605-624.

Lee, M. (2014). Achievement Goals, Emotions, and Foreign Language Performance in German and Korean Students. (Unpublished Doctoral Dissertation). University of Munich. Munich, Germany.

Li, C., Jiang, G., and Dewaele, J. (2018). Understanding Chinese high school students' foreign language enjoyment: Validation of the Chinese version of the foreign language enjoyment seate. System, 76, $183-196$.

Leung KC, Marsh HW, Craven RG, \& Abduljabbar AS. (2016). Measurement invariance of the self-description questionnaire II in a Chinese sample. European Journal of Psychological Assessment, 32, 128-139.

Lüdtke, O., Marsh, H. W., Robitzsch, A., \& Trautwein, U. (2011). A $2 \times 2$ taxonomy of multilevel latent contextual models: Accuracy-bias trade-offs in full and partial errorcorrection models. Psychological Methods, 16, 444-467.

MacIntyre, P. D., \& Gardner, R. C. (1994). The subtle effects of language anxiety on cognitive processing in the second language. Language Learning, 44, 283-305.

MacIntyre, P. D., Gregersen, T., \& Mercer, S. (2019). Setting an agenda for positive 
psychology in SLA: Theory, practice, and research. The Modern Language Journal, 103, 262-274.

Marsh, H. W., \& O’Neill, R. (1984). Self-Description Questionnaire III: The Construct Validity of Multidimensional Self-Concept Ratings by Late Adolescents. Journal of Educational Measurement, 21, 153-174.

Marsh, H. W., L“udtke, O., Nagengast, B., Trautwein, U., Morin, A. J. S., Abduljabbar, A. S., \& K"oller, O. (2012). Classroom climate effects: Methodological issues in the evaluation of group-level effects. Educational Psychologist, 47, 106-124.

Marsh, H. W., L“udtke, O., Robitzsch, A., Trautwein, U., Asparouhov, T., Muth'en, B. O., \& Nagengast, B. (2009). Doubly-latent models of school contextual effects: Integrating multilevel and structural equation approaches to control measurement and sampling error. Multivariate Behavioral Research, 44, 764-802.

Marsh, H. W., Seaton, M., Trautwein, U., Lüdtke, O., Hau, K. T., O'Mara, A. J., \& Craven, R.G. (2008). The big-fish-little-pond-effect stands up to critical scrutiny: Implications for theory, methodology, and future research. Educational Psychology Review, 20, 319350.

McDonald, R.P. (1970). Theoretical foundations of principal factor analysis, canonical factor analysis, and alpha factor analysis. British Journal of Mathematical and Statistical Psychology, 23, 1-21.

Möller, J., Zitzmann, S., Helm, F., Machts, N., \& Wolff, F. (2020). A Meta-Analysis of $\underline{\text { Relations Between Achievement and Self-Concept. Review of Educational }}$ Research, 90, 376-419. 
Moody, E., McIntosh, D. N., Mann, L. J., \& Weisser, K. R. (2007). More than mere mimicry? The influence of emotion on rapid facial reactions to faces. Emotion, 7, 447457.

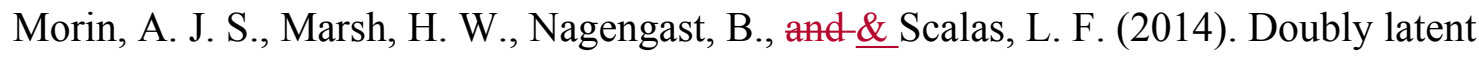
multilevel analyses of classroom climate: an illustration. Journal of Experimental Education, 82, 143-167.

Moskowitz, S., \& Dewaele, J-M. (2019). Is teacher happiness contagious? A study of the link between perceptions of language teacher happiness and student attitudes. Innovation in $\underline{\text { Language Learning and Teaching. Advanced online publication. }}$

Muthén, L. K., \& Muthén B. O. (1998 -2017). Mplus user's guide (8th ed.). Los Angeles, CA: Author.

Neumann, R., \& Strack, F. (2000). Mood contagion: The automatic transfer of mood between persons. Journal of Personality and Social Psychology, 79, 211-223. Noels, K. A., Pelletier, L. G., Clément, R., and Vallerand, R. J. (2000). Why Are You Learning a Second Language? Motivational Orientations and Self DeterminationTheory. Lange Learning, 50, 5785 . Pawlak, M., Kruk, M.,Zawodniak, J., \& Pasikowski, S., (2020). Investigating factors respensible for boredom in English classes: The ease of advanced learners. Sustem, 91,

\section{$\underline{102-122 .}$}

Parkinson, B. (2011). Interpersonal emotion transfer: Contagion and social appraisal. Personality and Social Psychology Compass, 5, 428-439.

Parkinson, B. (202019). Intragroup emotion convergence: Bbeyond contagion and social 
appraisal. Personality and Social Psychology Review, 24, 121-140.-Advanced onlinepublication. https://doi.org/10.1177\%/2F1088868319882596

Parkinson, B., \& Manstead, A.S.R. (2015). Current emotion research in social psychology: Thinking about emotions and other people. Emotion Review, 7, 371-380.

Parkinson, B., and $\underline{\&}$ Simons, G. (2009). Affecting others: Social appraisal and emotion contagion in everyday decision making. Personality and Social Psychology Bulletin, 35, 1071-1084.

Pawlak, M., Kruk, M., Zawodniak, J., \& Pasikowski, S. (2020). Investigating factors responsible for boredom in English classes: The case of advanced learners. System, 91,

\section{$\underline{\underline{102-122 .}}$}

Pekrun, R. (2006). The control-value theory of achievement emotions: Assumptions, corollaries, and implications for educational research and practice. Educational Psychology Review, 18, 315-341.

Pekrun, R., Goetz, T., Frenzel, A. C., Barchfeld, P., \& Perry, R. P. (2011). Measuring emotions in students' learning and performance: the Achievement Emotions Questionnaire (AEQ). Contemporary Educational Psychology, 36, 36-48.

Pekrun, R., Hall, N. C., Goetz, T., \& Perry, R. P. (2014). Boredom and academic achievement: Testing a model of reciprocal causation. Journal of Educational Psychology, 106(3), 696710.

Pekrun, R., and $\underline{\&}$ Meier, E. (2011). Task value questionnaire. Unpublished manuscript, Department of Psychology, University of Munich. Munich, Germany.

Pekrun, R., Murayama, K., Marsh, H. W., Goetz, T., \& Frenzel, A. C. (2019). Happy fish in little 
ponds: Testing a reference group model of achievement and emotion. Journal of Personality and Social Psychology, 117(1), 166-185.

Pekrun, R., and $\underline{\&}$ Perry, R. P. (2014). Control-value theory of achievement emotions. In R. Pekrun and L. Linnenbrink-Garcia (eds.), International Handbook of Emotions in Education (pp. 120-141). New York: Taylor and Francis.

Peng, J., and Woodrow, L. (2010). Willingness to communicate in English: A model in the Chinese EFL classroom context. Language Learning, 60, 834-876.

People's Education (2016). Chuzhong Yingyu Xinkebiao. [New curriculum standard for middle school English textbooks]. Beijing, People's Education Press.

Phung, L. (2017). Task preference, affective response, and engagement in L2 use in a US university context. Language Teaching Research, 21, 751-766.

Putwain, D. W., Pekrun, R., Nicholson, L. J., Symes, W., Becker, S., \& Marsh, H. W. (2018). Control-value appraisals, enjoyment, and boredom in mathematics: A

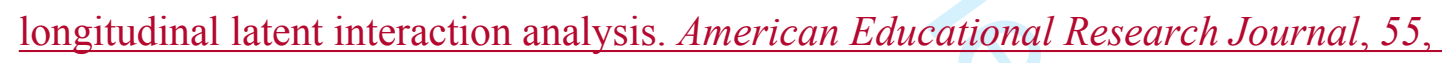
$\underline{1339-1368 .}$

Raykov, T., and \& Marcoulides, G. A. (2004). Using the Delta Method for Approximate Interval Estimation of Parametric Functions in Covariance Structure Models. Structural Equation Modeling, 11, 659-675.

Reyes, M. R., Brackett, M. A., Rivers, S. E., White, M., \& Salovey, P. (2012). Classroom Emotional Climate, Student Engagement, and Academic Achievement. Journal of Educational Psychology. 104, 700-712.

Saito, K., Dewaele, J., Abe, M., and $\underline{\&}$ In'nami, Y. (2018). Motivation, emotion, learning 
experience, and second language comprehensibility development in classroom settings:

A cross-sectional and longitudinal study. Language Learning, 68, 709-743.

Sardegna, V. G., Lee, J. and $\underline{\&}$ Kusey, C. (2018). Self-efficacy, attitudes, and choice of strategies for English pronunciation learning. Language Learning, 68, 83-114.

Scherer, K. R. (2013). The nature and dynamics of relevance and valence appraisals:

Theoretical advances and recent evidence. Emotion Review, 5, 150-162.

Shao, K. Q., Nicholson, L. J., Kutuk, G., \& Lei, F. (2020a). Emotions and instructed $\underline{\text { language learning: Proposing a second language emotions and positive psychology }}$ $\underline{\text { model. Frontiers in Psychology, Advanced online publication. }}$

Doi: $10.3389 /$ fpsyg. 2020.02142

Shao, K. Q., Pekrun, R., Marsh, H.W., \& Loderer, K. (2020b). Control-value appraisals, $\underline{\text { achievement Emotions, and foreign language performance: A latent interaction analysis. }}$ Learning and Instruction. Advanced online publication.

Doi: $10.1016 /$ j.learninstruc.2020.101356

Shao, K._Q., Pekrun, R., and $\underline{\&}$ Nicholson, L. J. (2019). Emotions in classroom language learning: What can we learn from achievement emotion research? System, 86, 102-121.

Shao, K._Q., Yu, W._H., and $\underline{\&}$ Ji, Z._M. (2012). The relationship between EFL students' emotional intelligence and writing achievement. Innovation in Language Learning and Teaching, 7, 107-124.

Shao, K._Q., Yu, W._H., and $\underline{\&}$ Ji, Z._M. (2013). An exploration of Chinese EFL students' emotional intelligence and foreign language anxiety. Modern Language Journal, 97, 919-931. 
Shirvan, M.E., \& Taherian, T. (2018). Longitudinal examination of university students' foreign language enjoyment and foreign language classroom anxiety in the course of general English: latent growth curve modeling. International Journal of Bilingual Education and Bilingualism. Advanced online publication. Doi:

$10.1080 / 13670050.2018 .1441804$

Teimouri, Y. (2017). L2 selves, emotions, and motivated behaviors. Studies in Second Language Acquisition, 39, 681-709.

Teimouri, Y., Goetze, J., and $\underline{\&}$ Plonsky, L. (2019). Second Language Anxiety and Achievement: A Meta-analysis. Studies in Second Language Acquisition, 41, 363-387. 


\title{
Social Psychological Accounts of Peer Emotion Transfer in EFL Classrooms: A Doubly \\ Latent Multilevel Analysis
}

\begin{abstract}
Based on theories of emotion contagion and social appraisal in interpersonal affect transfer and the control-value theory of achievement emotions, the present study examined associations between students' perceptions of peer emotions and their own self-perceived emotions in English as a foreign language (EFL) classrooms. Data were collected from 103 seventh to ninth grade classrooms $(N=3,643)$ using self-report questionnaires. Doubly latent multilevel structural equation modeling showed that perceived peer enjoyment, anxiety and boredom and students' corresponding emotions for language learning were positively related and that the effects of perceived peer enjoyment, anxiety and boredom on corresponding student emotions were mediated by control and value appraisals at the individual level. At the class level, however, the mediation effects were only significant for control appraisal as a mediator of effects on anxiety and value appraisal as a mediator of effects on boredom. Effects were robust across grade level, gender and previous language achievement. The discussion centers on the practical implications of peer emotion interactions for promoting foreign language development in classroom instruction.
\end{abstract}

Keywords: emotion, peer, interpersonal affect transfer, appraisal, language, classroom 


\section{Introduction}

Emotions are of critical importance for students' foreign language (FL) learning and achievement (Dewaele \& MacIntyre, 2014). Recent research has documented that both positive emotions (e.g. enjoyment, hope and pride) and negative emotions (e.g. anxiety, shame and boredom) can affect foreign/second language engagement and performance by influencing learners' interest, motivation, effort, self-regulation of learning, and the availability of cognitive resources for language tasks (Dewaele et al., 2018; Saito et al., 2018; Shao et al., 2020b; Teimouri, 2017). Previous research tended to address these emotions from an individualistic perspective; however, it can be assumed that students' FL emotions are not experienced in a social vacuum, but rather are influenced by other people such as peers and teachers in the micro-context of language classrooms (Shao et al., 2020a). The need to study emotional interactions among peers in the FL classroom has become even more significant given the fact that students spend the majority of their time with peers in their school life.

Social psychological theories of emotion contagion and social appraisal offers two useful accounts for explaining the phenomenon of peer emotion transmission in FL classrooms (Parkinson \& Manstead, 2015). Whereas emotion contagion postulates that a person's emotions can be automatically infected by their social partners' emotional states (Hatfield, Cacioppo, \& Rapson, 1994); social appraisal suggests that the influence of other people's emotions on a person depends on the relevant person's appraisals of the meaning of their social partners' emotions (Parkinson, 2011). In educational research, the control-value theory (CVT) of achievement emotions posits that appraisals of achievement-related control 
and value are the primary antecedents of students' emotions towards learning activities and outcomes (Pekrun, 2006). Both control and value appraisals are essential for an emotion to be instigated (Pekrun \& Perry, 2014). Moreover, CVT implies that control and value appraisals can mediate the effects of classroom features (e.g. teachers, peers and instruction quality) on students' achievement emotions (Pekrun, 2006). However, these assumptions have rarely been examined in the foreign language classroom. Combining the social appraisal and CVT perspectives raises the possibility that peer-to-peer emotional transfer is mediated by the control and value appraisals that are inferred from observed peer emotions. For example, observing classmates' enjoyment leads to the inference that they value their current learning activities, leading pupils to value and hence enjoy those activities too.

Although very few studies have explored the impact of classroom environment on students' emotions in the FL context (Cao, 2014; Gkonou, \& Miller, 2019; Khajavy et al., 2016), these studies have often treated teacher and peer variables at the individual level as if language learners and teachers are independent of each other. Students studying in the same class have the same teachers, perform the same activities at the same time, and share the same classroom atmosphere, thus, this represents a nested structure of data with students at the individual level (L 1) and class at the group level 2 (L2) (Khajavy, MacIntyre, \& Barabadi, 2018). Interpreting student-level variables as though they reflect class-level variables is a very common mistake in educational and language research (Cunnings, 2012; Marsh et al., 2012). Analyzing data at a single student level confounds the effects of the individual student and the classroom and implicitly assumes that the effects observed at one level generalize to another (Marsh et al., 2012). This statistical issue, however, can be 
addressed directly by using multilevel analysis and its recent development, doubly latent multilevel analysis wherein both student and class levels effects are estimated.

The present study extends previous research by considering the informational and affective consequences of perceived peer emotions on individual language learners' emotions. In particular, we consider two ways in which perceived peer FL enjoyment, anxiety and boredom may influence students' own corresponding emotions towards language learning, the first based on social appraisal (Parkinson \& Manstead, 2015), and the second based on emotion contagion (Hatfield et al., 1994). Moreover, based on CVT (Pekrun, 2006), we consider two types of cognitive appraisals, namely, perceived control and perceived value, as potential mediators in the process of social appraisal. Furthermore, benefiting from recent methodological advances in doubly latent multilevel analyses (Marsh et al., 2012), we investigated how students' self-perceived FL emotions are influenced by their perceptions of peer emotions at both the student level and the classroom level.

\section{Emotion Contagion and Social Appraisal in Emotion Transfer}

Emotion contagion and social appraisal are two influential accounts of interpersonal affect transfer in social psychology (Parkinson, 2011). Emotion contagion postulates a natural tendency to mimic other people's expressions and postural changes during interpersonal interaction. Self-perception of these copied movements in turn produces corresponding emotional experiences via interceptive feedback processes (Hatfield et al., 1994). For example, we may simply feel happy after interacting with a cheerful person. By contrast, social appraisal theory suggests that one person's emotion affects a second person's emotion 
because of its effects on the second person's appraisals. In particular, individuals may take other people's feelings into account when arriving at evaluations of the emotional significance of what is happening (Parkinson \& Manstead, 2015). For instance, we may become more anxious about an event when our companion's anxiety makes us aware of risks that we had not previously considered.

The distinction between these two perspectives hinges on the role of appraisals in interpersonal affect transfer. Social appraisal occurs because someone else's perceived affect carries information that alters our appraisal of the meaning of events and subsequent emotions. This implies that social appraisal may serve as the mediator in the influence of other people's emotions on our own emotions. In emotion contagion, however, we catch another person's affect automatically and without necessarily registering its personal significance (Parkinson \& Simons, 2009).

Ample evidence already supports the operation of these two processes in emotion transfer (Moody et al., 2007; Neumann \& Strack, 2000; Parkinson \& Simons, 2009). For example, Neumann and Strack (2000) attempted to test mood contagion in a series of experiments where participants listened to recordings of a happy, neutral, or sad voice. Mood was rated as better after exposure to the happy voice, but there were no corresponding effects of explicit registration of the other's expressed affect or awareness that affect had been influenced. On the other hand, Parkinson and Simons' (2009) diary research investigated interpersonal emotion transfer in everyday decision-making. Participants' anxiety about impending decisions was significantly affected by the reported anxiety of another person present at the time, and this affect transfer was partially mediated by 
appraisals of risk and importance.

Although these two perspectives have not been examined previously in the FL context, it seems likely that they are equally applicable in language classrooms (Shao et al., 2020a). For example, students may get excited when watching classmates enjoy using the FL to communicate with the teacher without thinking about the reasons behind their peers' enjoyment (contagion). This shared enjoyment may also change students' perception of value or sense of self-efficacy about speaking the target language, which may in turn have positive effects on their own enjoyment of practicing the FL orally (appraisal). By contrast, they may catch peers' anxiety immediately after seeing them speaking nervously in front of the language class. This may lead them to worry about possible negative evaluations of mistakes and undermine their confidence and interest in public speaking, which may further exacerbate their language anxiety. These assumptions are in line with Pekrun's (2006) proposition that the classroom environment can shape students' achievement-related appraisals and emotions.

\section{Control and Value Appraisals in Achievement Emotions}

Contemporary theories of emotion emphasize the pivotal role of cognitive appraisals for eliciting emotions (e.g. Scherer, 2013). In the same vein, the control-value theory of achievement emotions proposes that individuals experience specific achievement-related emotions when they feel in control, or out of control, of achievement activities and outcomes that are subjectively important, implying that control and value appraisals are the proximal determinants of these emotions (Pekrun, 2006; Pekrun \& Perry, 2014). High perceived 
control and positive perceived value of achievement activities and outcomes are assumed to elicit positive emotional experiences such as enjoyment or pride, whereas low control and negative value are expected to elicit negative emotions such as anxiety or boredom. So far, a number of studies have confirmed that positive achievement emotions are positively associated with students' control and positive value appraisals, while the opposite pattern has generally been found for negative achievement emotions (Goetz et al., 2010; Pekrun et al., 2011; Shao et al., 2020b).

Moreover, the control-value framework postulates that the affective impact of the social environment on achievement emotions is mediated by control and value appraisals (Pekrun, 2006). Accordingly, it is assumed that features of the learning environment that provide information related to controllability and academic values are of crucial importance for students' emotions. Consistent with this assumption, recent research has shown that a classroom environment conveying positive relationships, enjoyment and mastery goal orientation positively predicts students' academic self-efficacy, engagement and achievement and negatively predicts their anxiety at both individual and classroom levels (Arens, Morin, \& Watermann, 2015; Frenzel et al., 2018; Reyes et al., 2012). However, this research has focused exclusively on domain-general emotions or students' math-related emotions, and has neglected students' emotions in language learning.

In the present FL context, perceived peer emotions provide meaningful signals reflecting their appraisals of the language learning events. They may influence students' emotions either directly as a result of emotion contagion (Hatfield et al., 1994) or by affecting students' control-value appraisals (Pekrun \& Perry, 2014). Appraisal mediation 
would be consistent with the social appraisal account of interpersonal emotional influence in which the integration of information gleaned from others' emotions into one's own evaluation of an emotional situation plays an important role (Parkinson \& Simons, 2009). To date, there is a lack of empirical evidence documenting the relationships between perceptions of peer emotions and students' self-perceived appraisals and emotions in learning in general and FL learning in particular.

\section{Emotion Transmission in the FL Classroom}

Social-cognitive learning theories (Bandura, 1977; Pekrun, 2006) suggest that students' emotions are likely to be influenced by their peers' or teachers' thoughts, feelings and behaviors. Students may learn that a language-learning task is interesting by registering a teacher's enthusiasm, or by observing their peers' enjoyment of the learning content. By contrast, they may feel anxious about an FL exam due to teachers' past criticism, or as a result of watching peers' worried faces. In language classrooms, the need for students to communicate and interact with one another is greater than in other subjects due to the communicative demands of language acquisition. However, previous FL research has only tapped relations between teacher and student emotions, leaving the influence of peer emotions largely neglected. For example, studies have reported that teachers' foreign language anxiety (FLA) directly increases students' anxiety (Horwitz, 1996); whereas teachers' emotional warmth and positive characteristics (e.g. humor, friendliness) enhance students' positive feelings toward language learning (Borg, 2006; Dewaele, Magdalena, \& Saito, 2019). 
Despite language researchers' lack of attention to the emotional influence of peer emotions, some laboratory and field studies provide support for its operation. Fischer et al. (2004) investigated the impact of peers' emotional reactions on participants' own emotions in a feedback manipulation task. Results revealed that when others expressed anger, participants reported more intense anger themselves, and when others expressed sadness, participants reported more intense sadness themselves. The findings also showed that the extent of emotional assimilation depended on participants' interpersonal orientation and the extent to which others' emotions were recognized and processed. In a classroom setting, Delvaux et al. (2015) examined the influence of peer emotions on individual psychology students' emotions in small group tasks. Their results showed that individual students' anger and gratitude about the class assignments were influenced by their group members' correspomding collective emotions. Moreover, the emotion norms perceived by students within groups also shaped their emotions supporting the social appraisal account of emotion transmission (Parkinson, 2020).

Taken together, these findings suggest that students tend to experience and show similar emotions when they interact with each other in a shared situation. Importantly, this emotional assimilation is not simply the result of automatic mimicry, but rather involves using peers' emotions as a source of information about appraisal of emotional events (Fischer et al., 2004). However, these studies only investigated affect transfer among a small number of participants in group tasks, limiting the generalizability of their results. Furthermore, although Delvaux et al.’s (2015) study employed multi-level analysis to control for clustering effects at the group level, it did not take into account the influence of 
perceived peer emotions on individual students' emotions at both class and individual levels.

The study also used manifest variables to measure perceived peer emotions and student selfperception of emotions, which led to an underestimation of the correlations between them (Morin et al., 2014). To address these deficits, we conducted a large-scale quantitative study using doubly latent multilevel analysis to examine the emotion transfer among Chinese middle-school students in their English classrooms.

\section{Enjoyment, Anxiety and Boredom}

Research has shown that students experience a wide range of positive and negative emotions in general education (Frenzel et al., 2018; Goetz et al., 2010; Pekrun et al., 2011), but studies examining emotions other than anxiety are still at the nascent stage in second language research (Dewaele et al., 2018; Shao et al., 2020b). With the introduction of positive psychology to the field of SLA (see MacIntyre, Gregersen, \& Mercer, 2019), Dewaele and MacIntyre (2014) began to emphasize the role of positive emotions in general, and enjoyment in particular, in promoting and facilitating language development. Early studies have found that FL enjoyment positively correlated with learners' motivation, interest, effort and performance and negatively correlated with their FL anxiety (Satio et al., 2018; Shirvan \& Taherian, 2018; Teimouri, 2017). Importantly, measures of classroom atmosphere such as a teacher's FL accent, frequency of FL use, friendliness and students' attitudes towards their FL teacher were shown to be more predictive of FL enjoyment than FL anxiety (Dewaele et al., 2018; 2019). These findings suggest a need for further studies to examine a broader range of emotions in SLA as well as the influence of more classroom-specific antecedents 
including those relating to peers on students' FL emotions.

Anxiety has been the most-studied emotion in the SLA literature (see Teimouri, Goetze, \& Plonsky, 2019). FL anxiety can be defined as "worry and negative emotional reaction aroused when learning or using a second language" (MacIntyre \& Gardner, 1994, p. 284). Anxiety-related arousal distracts attention, causes diminished task-relevant cognition, and can affect the processing of L2 stimuli at all stages of language acquisition (see MacIntyre \& Gardner, 1994). To date, the majority of research evidence suggests a significant moderate negative association between anxiety and L2 performance (see Teimouri et al., 2019). Research has also shown that individual antecedents such as learners' demographics, characteristics, and task-related competence and value appraisals are important predictors of FL anxiety (Phung, 2017; Sardegna, Lee, \& Kusey, 2018; Shao, Yu, \& Ji, 2013). At the class level, Khajavy et al.'s (2018) recent study has demonstrated that peer and teacher support positively predicts students' FL enjoyment, but negatively predicts their FL anxiety.

Boredom is an emotion that is among the most frequently experienced in the classroom (Pekrun et al., 2014); however, it has seldom been examined in the second language context. FL boredom can be specified as "an unpleasant feeling characterized by lack of cognitive stimulation, low physiological arousal and a sense of disengagement toward the language tasks" (Shao, Pekrun, \& Nicholson, 2019, p. 4). Studies in educational research have shown that boredom has no less deleterious effects than anxiety on students' learning and performance (see Frenzel et al., 2007; Pekrun et al., 2014). Very recently, a few pioneering studies have begun to explore possible correlates of boredom in the FL classroom (e.g., Pawlak et al., 2020). Preliminary results show that factors such as disengagement, 
monotony, repetitiveness and lack of satisfaction and challenge contribute to students' boredom in language classes, and low achievers also report higher level of proneness to boredom than high achievers (Pawlak et al., 2020). The need for further research investigating boredom in the FL context has become apparent given the fact that SLA is a gradually developing process necessitating long-term efforts, motivation, patience, interests, concentration and the like (MacIntyre et al., 2019).

\section{Doubly Latent Multilevel Analysis}

It is very common in education and language research that the data have a hierarchical or nested structure (Cunnings, 2012; Marsh et al., 2009). For example, students are nested within the classrooms, and classrooms are nested within the schools. However, past classroom studies have suffered from two critical problems: (a) treating classroom constructs as a student-level (L1) variable in single-level analyses instead of a classroomlevel (L2) variable in multilevel analyses that control sampling error in the aggregation of L1 ratings to form L2 constructs (e.g., Khajavy et al., 2016); and (b) relying on manifestvariable models rather than latent-variable models that control measurement error at L1 and L2 (e.g., Delvaux et al., 2015). If researchers are interested in the effects of classroom variables, then the appropriate unit of analysis should be an L2 unit based on classroomlevel constructs (climate, teacher, or peer). Evaluation of the effects of classroom variables based on L1 student-level constructs is a classic ecological fallacy (see Marsh et al., 2009), as the effects observed at the individual student level may differ from those at the classroom level. A vivid illustration of this ecological fallacy comes from classroom research on the 
big-fish-little-pond effect (BFLPE; Marsh et al., 2008). This research shows that achievement at the individual-student level has a positive effect on academic self-concept, but school- or classroom-average achievement has a negative effect on academic selfconcept. That is, the effect of a student's achievement on his/her academic self-concept depends on the average achievement of other students in the class or school.

Applying multilevel analysis to research of FL classroom emotion transfer, it is very probable that the effects of perceived peer emotions on an individual student's achievement appraisals and corresponding emotions are related to the average emotions of other learners in the class. For example, an individual student studying in an FL class characterized by high enjoyment and low anxiety and boredom is likely to have higher perceived control and positive value toward language learning, which, in turn, have a positive influence on the student's own enjoyment and a negative influence on their own anxiety and boredom. It should be noted, however, that class-average control and value, as often measured by selfcompetence (e.g., self-concept and self-efficacy) and personal relevance (e.g., attainment value and utility value) related constructs, may have negative contextual effects on a student's own enjoyment and positive contextual effects on their own anxiety and boredom, similar to those identified in BFLPE (Marsh et al., 2012; Pekrun et al., 2019).

Given the nested data structure and the latent variables used in this study, we employed a recent development in multilevel analysis, doubly-latent multilevel analysis, to address these issues. A doubly latent multilevel analysis is based on latent variables with several indicator variables, rather than using single manifest variables. The latent variable scores are then nested within multiple levels. This approach is a combination of multilevel modeling 
and structural equation modeling (SEM). The advantage of doubly latent multilevel analysis lies in controlling for sampling error by considering the nested structure of the data as different scores of individual students (Level 1) are indicators of a latent class (Level 2) and controlling for measurement errors by including multiple indicators representing the latent constructs (Marsh et al., 2012).

\section{Hypotheses}

The research reviewed thus far suggests that there are positive links between perceived peer emotions and students' self-perceived emotions in the FL classroom. However, there is a lack of large-scale quantitative evidence about this relationship. Furthermore, regarding emotional transmission from peers to individual students, it is plausible that control-value appraisals are mediators of the relationships between perceived peer emotions and students' corresponding emotions. However, research has yet to examine social appraisal as a possible mediating mechanism linking perceived peer emotions and students' self-perception of emotions toward FL learning.

Addressing these research deficits, the present study aimed to explore the relationships between perceived peer emotions, control-value appraisals and students' achievement emotions in language classes. In analyzing the data, we took into account the multilevel structure of the data by estimating these relations both at the classroom and at the student levels to properly disentangle individual versus classroom components. At the class level, we also considered the contextual nature of the effects of appraisals on emotions. In sum, we 
tested the following hypotheses (see Figure 1):

Hypothesis 1. Perceived peer FL enjoyment, anxiety and boredom will positively predict students' corresponding enjoyment, anxiety and boredom (emotion transfer).

Hypothesis 2. Perceived peer FL enjoyment will positively predict students' control-value appraisals and perceived peer FL anxiety and boredom will have a negative influence on them.

Hypothesis 3. The relationships between perceived peer FL enjoyment, anxiety and boredom and students' corresponding emotions will be mediated by control-value appraisals (social appraisal) but still remain significant after controlling for the influence of appraisals (emotion contagion).

\section{Method}

\section{Participants and Procedures}

The sample consisted of 3,643 students $(54 \%$ male; mean age $=12.85, S D=.89)$ in 103 seventh to ninth grade classrooms from six middle schools in a city in Southeastern China. 477 participants $(12 \%$ of the total 4120$)$ were excluded from the final sample due to serious missing data (more than 50\%). The reason for this level of missing data was that students were asked to answer the questionnaire during the ten-minute class interval and some of them were unable to complete all items in this relatively short time given their young age. 
Among the six schools sampled, one was a school for migrant children from rural families, two were lower-middle level schools, the other two were upper-middle level schools, and one was an elite private school. Such a combination is representative of the current school structure in the city. As such, the students taking part came from a wide range of socioeconomic backgrounds, including both rural and city registered children. The average number of students per class was $35.37($ Minimum $=21$, Maximum $=55, S D=5.38)$. Students attended two English classes for 1.5 hours per day from Monday to Friday. Employing a teacher-centered approach, teachers were responsible for helping students acquire four basic skills (i.e., listening, speaking, reading and writing) in English and master the usage of a vocabulary list of 1500 to 2000 words in three years of study (People's Education, 2016).

Data were collected by trained research assistants during regular school days in the middle (early November) of the winter semester which typically begins in early September. At this point, students have definitely formed their perceptions of peers' emotions during English lessons and their appraisals and emotions about the subject. Moreover, all the instructions in this study asked students to report their class-related emotions and appraisals over the most recent two weeks so that these perceptions were more salient to them at the time of investigation. At the beginning of the survey, students were informed about the purpose and the voluntary nature of participating in this research, and told that they could withdraw from the survey any time during the data collection. Research assistants read aloud the instructions to students and were available to respond to any questions. Teachers were not present during data collection. Since one teacher taught at least two classes in the present 
sample, we randomly selected one class per teacher in order to avoid a possible three-level data structure. Students were informed about the general purpose of the research and its confidential nature. Written consent forms permitting students to participate in the study were obtained from the school principal.

\section{Measures}

Perceived peer emotions. Due to the lack of any existing questionnaire measuring perceived peer emotions, we developed a scale to assess students' perception of peer enjoyment, anxiety and boredom in FL classes. We modified items from the class-related Achievement Emotion Questionnaire (AEQ; Pekrun et al., 2011) which contains eight emotion subscales and a total of 80 items. Each perceived peer emotion was measured by five items selected from the original scale. The selection criteria for all items assessing the latent variables used in the present study were based on expert judgment, existing literature and consultation with authors' of the original scales (Marsh \& O'Neill, 1984; Pekrun et al., 2011). Following Marsh et al.'s (2012) recommendations, we used a uniform stem “My classmates...” for each item measuring perceived peer emotion (e.g. Enjoyment: "My classmates enjoy being in this English class." Anxiety: "My classmates feel nervous in this English class." Boredom: "My classmates get bored in this English class."). In this way, the referent is the classroom (or classmates as a group) and individual students' ratings are interchangeable in relation to the classroom level of the variable in that every student is instructed to rate the same construct (Morin et al., 2014). Students reported the extent to 
which they agreed with each statement using a 5-point Likert scale $(1=$ strongly disagree; 5 = strongly agree), and the scores were summed to form the perceived emotion indices (enjoyment $\alpha=.88$, anxiety $\alpha=.82$, boredom $\alpha=.84$ ).

Control and value appraisals. Students' perceived control was measured by a shortversion of Marsh and O’Neill's (1984) Self-Description Questionnaire (SDQ), which originally included 42 items measuring students' academic self-concept in different facets (general, school, English and math). The SDQ has also been validated in a Chinese highschool context in Hong Kong (Leung et al., 2016). The adapted scale consisted of six items assessing students' self-concept concerning the subject of English (e.g. I have always done well in English). Participants responded to a 5-point scale $(1=$ strongly disagree to $5=$ strongly agree), and the internal consistency of the scale was high in the present study ( $\alpha$ $=.89$ ). Students' perceived lesson value was assessed using a six-item version of the Task Value Questionnaire (Pekrun \& Meier, 2011). This scale measures students' intrinsic, utility and attainment value (two items for each dimension) related to English learning (e.g., "I find learning English is very interesting"; "I think learning English is very useful for me"; "It is important to me get good grades in this course". 1 = strongly disagree, $5=$ strongly agree). Scores on the six items were summed to form the value index $(\alpha=.77)$.

Achievement emotions. Students' achievement emotions were assessed using the above mentioned course-related emotion scales of the Achievement Emotion Questionnaire (Pekrun et al., 2011). By modifying the instruction of the original AEQ, the new measure provided a description of the English class related situation referred to in the assessment and then asked respondents to report how they felt when sitting in the language course. The 
scales assessed three emotions using five items for each emotion: enjoyment (e.g., "I enjoy participating in this English class so much that I get energized"), anxiety (e.g., "I get scared that I might say something wrong in this English class") and boredom (e.g., "I find this English class fairly dull"). Participants responded on a 1 (not at all) to 5 (very much) scale, and the scores were summed to form the emotion indices (enjoyment $\alpha=.85$, anxiety $\alpha$ $=.80$, boredom $\alpha=.84)$.

Covariates. At the student level, gender was included as a potentially confounding covariate because girls tend to report both more enjoyment and more anxiety in academic learning (Frenzel et al., 2007; Pekrun et al., 2011). At the classroom level, grade was included as a covariate because past research has demonstrated that this variable was negatively associated with students' perception of classroom environment (Morin et al., 2014). Moreover, students' previous English achievement was included as a covariate at both individual and class levels. Previous achievement has been shown to have significant effects on students' academic self-concept and achievement emotions (Marsh et al., 2009; Pekrun et al., 2014).

The final questionnaire contained demographic questions and a total of 62 scale items. All scales used in the present investigation were translated from English to Chinese (see supplementary material). The English version of the questionnaire was used as the basis for translation by one educational psychologist and one bilingual English professor. The translations were then blindly back-translated by two bilingual $\mathrm{PhD}$ students in educational psychology. After this, both Chinese and English versions of the questionnaire were presented to a translation expert and another bilingual English professor, who further 
reviewed and polished the wording of the items to reach the closest possible equivalence across language versions. Finally, a pilot-test was also conducted on 104 students to check the wording and internal consistency of the new instrument. These participants were excluded from the final sample. All items and scales demonstrated good item-total correlation and reliability in the pilot-test.

\section{Data Analysis Strategy}

In the present study, data from 3,643 participating students were nested within data from 103 classrooms and corresponding teachers. Therefore, testing our assumptions required a multilevel analysis approach. For perceived peer emotions, students were asked to directly rate the level 2 (L2) construct on items having the classroom as the referent, i.e. students rated all their classmates' emotions as a whole in the FL classroom, thus providing a measure of shared emotional experience among all the students within the same class. The aggregated perceptions reflect the same underlying L2 constructs or climate, and students' ratings within the same class are theoretically 'interchangeable' (Marsh et al., 2012). Thus, it seemed more appropriate to measure this variable at the classroom level. However, we consider that students' perception of peer emotions is also an individual characteristic unique to the specific person (Arens et al., 2015; Frenzel et al., 2018). This part of level 1 (L1) residual variances reflects individual differences in perceptions of classroom emotions that are not accounted for by the shared emotional experience at L2. From this perspective, it is best to model the proposed relationships between peer (i.e. perceptions of peers) and 
student (i.e. individual self-perception) emotions at both individual and classroom levels.

For control-value appraisals and achievement emotions, students were asked to rate the L1 construct on items with the individual student as the referent. Here, the L2 classroom levels of these variables are based on the class-average aggregates of individual student L1 characteristics that are specific to each person, and not interchangeable with other students in the class (Morin et al., 2014; e.g., class-average achievement, class-average SES, student gender). Thus, these measures represent contextual variables similar to student achievement and self-concept as in the above mentioned BFLPE (Marsh et al., 2008). This raises the possibility that class-average control and value appraisals may have a negative effect on students' enjoyment but a positive effect on their anxiety and boredom after controlling for individual level of control and value. This contextual effect needs to be properly estimated by calculating an additional parameter representing the difference between the L2 and L1 coefficients, providing a direct estimate of contextual effects (Enders \& Tofighi, 2007), with the multivariate delta method (e.g., Raykov \& Marcoulides, 2004). Similarly, the indirect effects of classroom level perceived peer FL emotions on student corresponding emotions as mediated by control-value appraisals need to be calculated while taking into account the contextual nature of the effects of control-value appraisals on emotions.

Mplus 8.0 (Muthén \& Muthén, 1998-2017) was used to construct our doubly-latent multilevel structural equation models (ML-SEM). The ML-SEM approach has the advantage of taking into account measurement error and sampling error at both levels and testing the hypothesized direct and indirect effects simultaneously at each level while controlling for the influence of the other (Marsh et al., 2009). Moreover, employing this method, the 
validity and reliability of the measures can also be assessed across the two levels (Morin et al., 2014). In addition, we relied on the full information maximum likelihood (FIML) method implemented in Mplus, rather than a quasi-listwise deletion strategy, to handle missing data (Enders, 2010). FIML, especially when used in conjunction with robust Maximum Likelihood (MLR) estimator, has been found to result in unbiased parameter estimates under even very high levels of missing data, and thus better represents the entire sample, rather than just the subsample of students who have no missing data. MLR has been found to be efficient in the estimation of latent-variable models based on either normally or non-normally distributed responses and items rated on scales including five or more response categories (Muthén \& Muthén, 1998-2017).

\section{Preliminary Verification of Statistical Requirements}

In doubly latent multilevel models, in addition to multicollinearity at level 1 and level 2, the reliability of the class aggregates, and of the constructs at L1 and L2, together with the verification that the a priori measurement model fits the data well at both levels are important statistical requirements that should routinely be checked. First, in order to facilitate interpretation of the results and to reduce non-essential multicollinearity, all variables were standardized before analysis, and variables used only at L1 were grand mean centered whereas variables modelled at both levels were group mean centered (Marsh et al., 2009). We also directly performed systematic tests which showed that both Tolerance $(>1)$ and VIF $(<2)$ values remained reasonably low. Thus, there were no potential problems of 
multicollinearity in individual ratings of the constructs used in the present investigation.

Next, to determine whether aggregated individual-level ratings of students' emotions, appraisals and perceived peer emotions were reliable indicators of the respective class-level constructs, we used the intraclass correlation coefficient Type 1 and 2 (Bliese, 2000). ICC1 refers to the agreement between any pair of students within the same class and also reflects the proportion of the total variance that occurs at the second level of analysis. ICC1 thus provides an estimate of the within-class homogeneity of aggregated group-level constructs. Values of .05 or above for ICC1 can be regarded as evidence that there are adequate grouplevel properties of a variable to warrant aggregation (Gavin \& Hofmann, 2002). Whereas ICC1 can be interpreted as the reliability of an individual student's rating as an indicator of a class-level variable, ICC2 provides an estimate of the reliability of the class-mean or classaggregated average rating (Lüdtke et al., 2006). ICC2 values of approximately .70 are considered to indicate sufficient reliability of class-level aggregated scores (Marsh et al., 2012). These indices were satisfactory in this study and thus justified the assessment of all the variables at class level: enjoyment $(\mathrm{ICC} 1=.12, \mathrm{ICC} 2=.82)$, anxiety $(\mathrm{ICC} 1=.09, \mathrm{ICC} 2$ $=.78)$, boredom $(\mathrm{ICC} 1=.17, \mathrm{ICC} 2=.88)$, perceived control $(\mathrm{ICC} 1=.08, \mathrm{ICC} 2=.76)$, perceived value $(\mathrm{ICC} 1=.15, \mathrm{ICC} 2=.86)$, perceived peer enjoyment $(\mathrm{ICC} 1=.13, \mathrm{ICC} 2$ $=.84)$, perceived peer anxiety $(\mathrm{ICC} 1=.09, \mathrm{ICC} 2=.77)$, perceived peer boredom $(\mathrm{ICC} 1$ $=.16, \mathrm{ICC} 2=.87)$.

Further, following Marsh et al.'s (2012) recommendation, we conducted multilevel confirmatory factor analyses (ML-CFA) for all six structural models tested in the study to check whether the a priori factor model holds at both L1 and L2. Traditional cutoff criteria 
indicative respectively of excellent and adequate fit to the data were used (Byrne, 2011): (i)

CFI (comparative fit index) and TLI (Tucker-Lewis index) $\geq .95$ and $\geq .90$; (ii) RMSEA (root mean square error of approximation) $\leq .06$ and $\leq .08$. Model fit indices demonstrated that they provided very good fit to the data (see Table 3).

Finally, based on parameters obtained from the above ML-CFA models, we computed McDonald's (1970) omega $(\omega)$ to estimate the reliability of different latent constructs at level 1 and level 2. Compared with traditional scale score reliability estimates (e.g., alpha), $\omega$ has the advantage of taking into account the strength of association between items and constructs as well as item-specific measurement errors and to be applicable to the estimates obtained at both L1 and L2 based on level-specific variance-covariance matrices (Morin et al., 2014). $\Omega$ coefficients are interpreted as any other composite reliability coefficients (above .70 indicates sufficient). These indices were fully satisfactory for enjoyment $(\omega=$ $.84 / .92$ at $\mathrm{L} 1 / \mathrm{L} 2)$, anxiety $(\omega=.79 / .93)$, boredom $(\omega=.80 / .96)$, perceived control $(\omega=$ $.88 / .97)$, perceived value $(\omega=.75 / .96)$, perceived peer enjoyment $(\omega=.86 / .98)$, perceived peer anxiety $(\omega=.83 / .95)$ and perceived peer boredom $(\omega=.81 / .96)$. It should be noted that these coefficients operated independently at L1 and L2, and the reliability were substantially higher at L2. In other words, when estimating L2 constructs, doubly latent models partialed out the unreliability of agreement between students forming each class and the classaggregated ratings of these latent variables were more reliable than individual ratings (Marsh et al., 2012).

\section{Results}




\section{Preliminary Analyses}

Table 1 displays the descriptive statistics for each of the variables in the study. The scores on all variables except for previous English achievement (negatively skewed) were normally distributed and there were sufficient variations within each variable as indexed by their standard deviation and range. Students generally experienced more enjoyment than anxiety or boredom in their English class. Multiple group mean comparison showed that the differences between each pair of the three emotions were significant, $F(2,10917)=2348.86$, $p<.001$. Similar differences also applied when comparing students' perceptions of peer enjoyment, anxiety and boredom, $F(2,10885)=2581.71, p<.001$. Moreover, students tended to assign a relatively high value to learning English but reported only a moderate level of control over their learning of this subject, $t(7277)=34.93, p<.001$.

Table 2 presents the Pearson product-moment correlations between study variables at both individual and classroom levels. Students' FL enjoyment, anxiety and boredom were positively linked with corresponding perceptions of peer enjoyment, anxiety and boredom. Both control appraisal and value appraisal were positively related to student and perceived peer enjoyment, but were negatively related to student and perceived peer anxiety and boredom in language classrooms. Student and perceived peer FL enjoyment were negatively related to student and perceived peer anxiety and boredom. All the directions of correlations were the same and ranged from moderate to strong across the two levels. These correlations provide preliminary evidence for the hypothesized relationships between perceived peer emotions, appraisals and student emotions. 
The results also confirm the appropriateness of the included control variables, which were significantly (weakly for gender and performance but moderately for grade) related to perceived peer FL emotions, control-value appraisals and student emotions.

\section{ML-SEM Analyses}

To test Hypothesis 1 that perceived peer FL enjoyment, anxiety and boredom would be positive predictors of students' corresponding enjoyment, anxiety and boredom, we regressed student emotions on corresponding perceived peer emotions at the individual level and at the classroom level in three separate models (i.e., perceived peer emotion was the independent variable and their corresponding student emotion was the dependent variable in each model). Results from multilevel structural equation modelling showed that there was a significant positive main effect of perceived peer FL enjoyment on student enjoyment at both individual $(\beta=.68, p<.001)$ and class levels $(\beta=.73, p<.001)$ after controlling for all covariates. Similarly, perceived peer FL anxiety was a significant positive predictor of student anxiety (individual/classroom; $\beta=.65, p<.001 / \beta=.71, p<.001$ ) and perceived peer FL boredom was a significant positive predictor of student boredom (individual/classroom; $\beta=.64, p<.001 / \beta=.44, p<.001$ ) across the two levels. Thus, all measured peer emotions were positively associated with the corresponding student emotions, as predicted.

In a next step, we separately added perceived control and perceived value to both the individual and the classroom levels of each model to test the associations between perceived 
peer emotions and control-value appraisals (Hypothesis 2). At the individual student level, perceived peer FL enjoyment positively predicted control appraisals $(\beta=.45, p<.001)$ and value appraisals $(\beta=.55, p<.001)$. By contrast, perceived peer FL anxiety and boredom negatively predicted both appraisals of control (anxiety/boredom; $\beta=-.40, p<.001 / \beta=-.28$, $p<.001$ ) and value (anxiety/boredom; $\beta=-.25, p<.001 / \beta=-.45, p<.001$ ). There were also corresponding effects at the classroom level. Perceived peer FL enjoyment was again a significant positive predictor of control appraisal $(\beta=.50, p<.001)$ and value appraisal $(\beta$ $=.66, p<.001)$, and perceived peer FL anxiety and boredom were again both significant negative predictors of control (anxiety/boredom; $\beta=-.41, p<.001 / \beta=-.53, p<.001$ ) and value (anxiety/boredom; $\beta=-.27, p=.04 / \beta=-.46, p<.001$ ) appraisals. Thus, peer emotions influenced student appraisals at both levels as predicted.

In the third step, we explored the relationship between perceived peer emotions and students' corresponding emotions in more detail by testing Hypothesis 3, which predicted that this relationship should be mediated by control and value appraisals but remain significant after controlling for these mediators. Each student emotion was regressed on control appraisal and value appraisal separately in the above six models. The goodness of fit indices for the final six ML-SEM models are reported in Table 3. As can be seen, the inspected range of fit indices demonstrate that these models have a good fit to the data. Finally, Table 4 presents all the unstandardized and standardized path coefficients obtained from these final models.

At the individual level, control appraisal had a significant positive effect on student FL enjoyment but a significant negative effect on student FL anxiety and boredom when 
controlling for corresponding perceptions of peer enjoyment, anxiety and boredom.

Moreover, the influences of perceived peer FL enjoyment, anxiety and boredom on students' corresponding enjoyment, anxiety and boredom were reduced but still significant when control appraisal was added to each model as another predictor of students' emotions. Mediation analyses further confirmed that the indirect effects of perceived peer emotions on students' corresponding emotions through control appraisal were significant for FL enjoyment $(\beta=.16, p<.001)$, anxiety $(\beta=.12, p<.001)$ and boredom $(\beta=.06, p<.001)$. Similarly, value appraisal was a significant positive predictor of student FL enjoyment but a significant negative predictor of student FL anxiety and boredom after controlling for corresponding perceived peer emotions. The effects of perceived peer FL enjoyment, anxiety and boredom on students' corresponding enjoyment, anxiety and boredom remained significant after controlling for the influence of value appraisal. The mediating effects of value appraisal in the relationship between perceived peer emotions and corresponding students' emotions were significant for FL enjoyment $(\beta=.22, p<.001)$, anxiety $(\beta=.04, p$ $=.004)$ and boredom $(\beta=.18, p<.001)$.

At the classroom level, the effects of control appraisal on students' emotions were reduced to nonsignificant for FL enjoyment and boredom but became significantly positive for FL anxiety when taking account of the contextual nature of this relationship and controlling for the influence of corresponding perceived peer emotions. The effects of perceived peer FL enjoyment, anxiety and boredom on students' corresponding enjoyment, anxiety and boredom were diminished but still significant after controlling for control appraisal. The only possible mediation effects of control in the relationship between 
perceived peer FL anxiety and student anxiety were significant $(ß=-.13, p=.027)$. On the other hand, value appraisal was no longer a significant predictor of FL enjoyment and anxiety but became a significant positive predictor of FL boredom when taking into account the contextual effects and controlling for corresponding perceived peer emotions. The influences of perceived peer FL enjoyment, anxiety and boredom on students' corresponding enjoyment, anxiety and boredom were lessened but remained significant after controlling for value appraisal. Mediation analyses showed that the indirect effects of perceived peer FL boredom on student boredom through value appraisal were significant $(ß=-.24, p=.01)$.

\section{Discussion}

The present study showed that students' perceptions of peer enjoyment, anxiety and boredom were positively linked with their own enjoyment, anxiety and boredom in language classes, even when controlling for students' gender, grade, and previous English achievement. This is in line with social-cognitive learning theory's (Bandura, 1977; Pekrun, 2006) assumption that the ongoing social interactions between peers and students in the classroom are likely to influence students' cognition, emotions and behaviors. It also supports an overall emotion transfer from peers to students in the FL classroom (Cao, 2014). Moreover, this relationship was found to be robust across student and class levels. This confirms the appropriateness of treating perceived peer emotions as classroom climate constructs as well as individual specific characteristics.

Consistent with our hypotheses, we found that control and value appraisals partially 
mediated the relationships between perceived peer FL enjoyment, anxiety and boredom and students' corresponding emotions. However, due to the contextual effects of appraisals on achievement emotions, control-value appraisals had differential effects on students' FL enjoyment, anxiety and boredom at the individual level and at the classroom level. Specifically, at the personal level, both control and value appraisals had positive effects on students' FL enjoyment but negative impacts on students' FL anxiety and boredom. The partial mediating effects of either control appraisal or value appraisal in the relationships between perceived peer emotions and students' corresponding emotions were all positively significant. This is in line with both the emotion contagion and the social appraisal accounts of interpersonal affect transfer (Hatfield et al., 1994; Parkinson \& Manstead, 2015) as well as the mediation assumption posited by the control-value theory of achievement emotion (Pekrun, 2006; Pekrun \& Perry, 2014).

When a student senses his/her peers' FL emotions on an individual basis, higher perceived peer enjoyment and lower perceived peer anxiety and boredom have positive influences on the student's control and value appraisals, which in turn result in higher levels of student enjoyment and lower levels of student anxiety and boredom (Shao et al., 2020a). Perceived peer FL enjoyment, anxiety and boredom may also be directly contagious to students' corresponding emotions without the influences of perceived control and value. These perceptions of language appraisals and emotions represent individual characteristics unique to each student independent of the shared classroom level effects (Morin et al., 2014).

At the classroom level, control appraisals had positive effects on students' FL anxiety 
and value appraisals had positive effects on students' FL boredom. The class-level positive effects of appraisals on FL emotions can be explained by the afore-mentioned "big-fishlittle-pond effect" (Marsh et al., 2008), which has also been replicated in many emotion studies demonstrating that class-average achievement can have negative contextual effects on students' enjoyment and positive contextual effects on their anxiety and boredom (Arens et al., 2015; Pekrun et al., 2019). Although the present study measured students' selfreported competence, research has shown that students' academic self-concept tends to have high correlations with their actual performance (see Möller et al., 2020 for a meta-analysis). This indicates that the higher the class's perceived average competence in English language was, the higher students' anxiety toward language learning was. Similarly, the higher the class's perceived average valuation of English language was, the higher students' boredom was in relation to the learning activity.

One explanation for these findings may be that they reflect the current middle school education in China, which overemphasizes the competitiveness and the attainment value of high-stake English exams. Students studying in high FL competence classes are surrounded by peers who have high-mean ability and scores in English, which results in relatively low individual self-confidence for English learning (Marsh et al., 2012). This may lead individual students to feel nervous and bored about English study. High class-average competence and value may also correspond to higher achievement demands in the respective class and probably also to higher pacing (Frenzel et al., 2007), which in turn seems to positively influence students' experience of anxiety and boredom when learning English in that class. Importantly, the present study extends previous findings by showing that emotion 
contagion and social appraisal processes may operate not only at the individual level but also at the collective level (Borg, 2006; Delvaux et al., 2015). It also contributes to existing literature by demonstrating that control and value appraisals had the opposite effects on students' FL emotions at the class level to those operating at the individual level.

Overall, our data demonstrated that perceived peer FL enjoyment had positive influences on students' control and value appraisals and on own enjoyment at individual and class levels while the opposite trend was observed for perceived peer FL anxiety and boredom. This implies that peers do make a difference to students' emotional experiences in the language classroom and may also affect students' cognitive appraisals of FL tasks (Khajavy et al., 2018; Shao et al., 2019). Moreover, the significant mediated effects of perceived peer emotions on students' corresponding emotions through appraisals add to the literature on peer affect transfer and provide evidence regarding potential underlying processes in FL classrooms (Delvaux et al, 2015). Specifically, peer FL emotions may impact students' self-perception of emotions either directly through automatic contagion (Moskowitz \& Dewaele, 2019) or indirectly through influencing their control and value appraisals (Parkinson \& Manstead, 2015; Shao et al., 2019), which in turn lead to different levels of language-related emotional experiences.

\section{Practical Applications of Research Findings}

The findings from the current study demonstrated that positive peer emotions have the potential to improve students' control-value appraisals and emotions at the level of the FL 
classroom as a whole, thus resulting in improvements for individual students within each classroom. This suggests that student FL interventions might profitably target the emotional climate of the whole class. For example, FL teachers can create a positive emotional atmosphere for language learning by demonstrating that the classroom is a valuable place to be and by being enthusiastic about acquiring the target language (Shao, Yu, \& Ji, 2012). Teachers should not only be effective at helping students solve problems in FL learning but also be highly aware of, and responsive to, students' social and emotional needs in the language acquisition process. If teachers notice signs of students' anxiety in the FL classrooms, they may adjust their instructional strategies by showing a sense of caring for students' negative feelings, providing delayed error correction, and emphasizing the positive value of making mistakes in language acquisition, so that students can feel comfortable using the target language (Gkonou \& Miller, 2019; Shao et al., 2013).

Moreover, one of the key considerations in building a positive classroom environment is that teachers make language learning an enjoyable rather than boring experience for students. Teachers can design interesting and challenging language tasks that allow students to develop a sense of autonomy and experience flow while filling the knowledge gap (Dewaele et al., 2019). It is also advised that teachers incorporate more innovative and stimulating teaching techniques into the language curriculum (e.g., technology-based learning, movies, role play, participating in fictional talk shows or live interviews etc; Hwang et al., 2017; Shao et al., 2019). For example, teachers may select different types of background music to match teaching content, students' preferences and learning contexts. The fine-tuned music may hit the emotional sweet spot of language learners that facilitates 
their language learning and engagement (Kang \& Williamson, 2014).

Furthermore, FL teachers can nurture positive peer emotions by promoting cooperative learning in and out of the classroom using cognitive scaffolding strategies such as requesting assistance, other-correction, and negotiation of meaning (Gagné \& Parks, 2013). When students work together toward the same learning goals, they start to build mutual support and shared responsibility with peers, and eventually develop a form of positive interdependence in which the language success of one student depends upon the success of all other students (Johnson \& Johnson, 2009). Such a language classroom is characterized by a sense of connectedness and belongingness, enjoyment and enthusiasm, and respect (Reyes et al., 2012). As a result, students feel more cheerful and competent in FL learning, and become more successful language learners.

Finally, another way to achieve a positive classroom climate is for teachers to openly express their personal enjoyment of language learning and teaching to their students. Research has demonstrated that teachers' expressed positive emotions such as enjoyment of teaching can significantly influence students' enjoyment of learning through emotional contagion (Frenzel et al., 2018; Moskowitz \& Dewaele, 2019). Thus, FL teachers are advised to be aware of their own emotions in class, up-regulate their pleasant emotions, and adopt an enthusiastic teaching style in order to create positive emotion interactions with students in language classrooms (Frenzel et al., 2018). Teachers' active cultivation of a sense of humor, friendliness and empathy are likely to generate more positive emotions for them and help students become happy, confident and proud language learners (Shao et al., 2013). 


\section{Limitations and Future Directions}

Some limitations of the present study may be used to suggest directions for future research. First, the use of cross-sectional data in the present study can only provide a snapshot of the highly dynamic emotional experiences during the FL learning process. Students may have very different feelings at certain times of the academic semester, especially at the start, middle, and end of a term. Future research could include a longitudinal approach such as the latent growth curve model that could compare results of questionnaires from two or three different time points (Shirvan \& Taherian, 2018). The predictive design of peer emotions on students' appraisals and emotions we used in the present EFL context is also limited due to the synchronous assessment of the study variables at one time point. While the proposed effects of peer FL emotions on students' control-value appraisals and corresponding emotions are theoretically plausible and supported by the current data, the reverse order of effects is also conceivable. Thus, it would be interesting for future research to use repeated measures to address potential reciprocal effects between peer FL emotions, student appraisals and emotions (Delvaux et al., 2015; Pekrun et al., 2014).

Second, as all the variables in the present study were assessed by self-reported questionnaire which are susceptible to response bias, the predictive effects found in the present FL setting may be inflated by common method variance (Donaldson et al., 2000). Although self-ratings have the unique advantage of accessing internal feelings and thoughts, 
the subjective nature of these measures is often difficult to control. Future research should also include objective measures such as implicit measures of emotions, EEG or fMRI to assess appraisals and emotions. For instance, researchers may use video observation to record students' emotions in the FL classes and match the transcribed data with other instruments to analyze the proposed hypotheses (Reyes et al., 2012). Researchers may also ask teachers or parents to report students' language appraisals and emotions as an alternative approach to assessment.

Third, the present study used a rather molar approach for assessing relationships between peer and student emotions, which were both assessed in a trait-like manner with regards to a year-long English class. A trait-like assessment is meaningful as it captures the overall emotional tone in classrooms. However, it cannot embrace micro-processes that likely are at work in interpersonal transmission of emotions. Studies using a more finegrained experience sampling approach addressing appraisals and emotions in a specific lesson or a period of time (e.g. before an FL exam) could be designed to further explore the underlying emotion contagion and social appraisal processes in the transfer of affect between peer and students in FL classrooms (see Goetz et al., 2010).

Fourth, the task value scale used to measure perceived value in the present research contains only two items for each dimension (intrinsic value, attainment value and utility value; Pekrun \& Meier, 2011) which makes it unfeasible to form latent variables for each value subscale (Muthén \& Muthén, 1998; 2017). Conceptually, these three dimensions represents different facets of value that have moderately strong correlations with one another (Putwain et al., 2018). For example, a student who likes reading English texts may not 
necessarily consider it important to get a good grade in the English exam. Therefore, it may be important that future research uses more items to measure each value dimension in order to acquire a more nuanced understanding of the relations between different facets of value appraisal and discrete emotions in FL classrooms.

\section{Conclusion}

The findings of the present study indicate that perceptions of peer emotions and students' self-perceived emotions are closely linked by ways of emotion contagion and social appraisal in English classrooms. Insights into such processes underlying affective interaction between peers and individual students are of crucial importance since emotionally positive FL classrooms are likely to also be successful language classrooms. We have shown that when an FL classroom is characterized by higher perceived peer enjoyment and lower anxiety and boredom, students feel more in control and appreciate more of the learning subject, which should result in more positive affective experiences during language learning. This suggests that FL success is at least partly contingent upon the emotional components of the language learning environment. Thus, enhancing pleasant emotions and moderating unpleasant emotions at the classroom level should be an important goal of instruction for FL teachers and educators. FL classrooms filled with enjoyment of learning likely provide optimal contexts for meeting acquisition challenges and promoting language development and achievement. 


\section{References}

Arens, A.K., Morin, A.J.S., \& Watermann, R. (2015). Relations between classroom disciplinary problems and student motivation: Achievement as a potential mediator? Learning and Instruction, 39, 184-193.

Bandura, A. (1977). Social learning theory. Englewood Cliffs, NJ: Prentice Hall.

Bliese, P. D. (2000). Within-group agreement, non-independence, and reliability: Implications for data aggregation and analysis. In K. J. Klein and S. W. Kozlowski (Eds.), Multilevel theory, research, and methods in organizations (pp. 349-381). San Francisco, CA: JosseyBass.

Borg, S. (2006). The distinctive characteristics of foreign language teachers. Language Teaching Research, 10, 3-31.

Byrne, B.M. (2011). Structural equation modeling with Mplus: Basic concepts, applications, and programming. New York: Routledge/Taylor \& Francis.

Cao, Y. (2014). A socio-cognitive perspective on second language classroom willingness to communicate. TESOL Quarterly, 48, 789-814.

Cunnings, I. (2012). An overview of mixed-effects statistical models for second language researchers. Second Language Research, 28, 369-382.

Delvaux, E., Vanbeselaere, N., \& Mesquita, B. (2015). Dynamic Interplay Between Norms and Experiences of Anger and Gratitude in Groups. Small Group Research, 46, 300-323.

Dewaele, J.-M., \& MacIntyre, P.D. (2014). The two faces of Janus? Anxiety and enjoyment in the foreign language classroom. Studies in Second Language Learning and Teaching, 4, $237-274$. 
Dewaele, J.-M., Witney, J., Saito, K., \& Dewaele, L. (2018). Foreign language enjoyment and anxiety: The effect of teacher and learner variables. Language Teaching Research, 22, 676697.

Dewaele, J.-M., Magdalena, A. F., \& Saito, K. (2019). The effect of perception of teacher characteristics on Spanish EFL learners' anxiety and enjoyment. The Modern Language Journal, 103, 412-427.

Donaldson, S. I., Thomas, C. W., Graham, J. W., Au, J. G., \& Hansen, W. B. (2000). Verifying drug abuse prevention program effects using reciprocal best friend reports. Journal of Behavioral Medicine, 23, 585-601.

Enders, C. K. (2010). Applied missing data analysis. New York, NY: Guilford Press.

Enders, C. K., \& Tofighi, D. (2007). Centering predictor variables in cross-sectional multilevel models: A new look at an old issue. Psychological Methods, 12, 121-138.

Fischer, A. H., Rotteveel, M., Evers, C., \& Manstead, A. S. R. (2004). Emotional assimilation: How we are influenced by others' emotions. Cahiers de Psychologie Cognitive, 22, $223-$ 245.

Frenzel, A. C., Becker-Kurz, B., Pekrun, R., Goetz, T., \& Lüdtke, O. (2018). Emotion transmission in the classroom revisited: A reciprocal effects model of teacher and student enjoyment. Journal of Educational Psychology, 110, 628-639.

Frenzel, A. C., Thrash, T., Pekrun, R., \& Goetz, T. (2007). Perceived learning environment and students' emotional experiences: a multilevel analysis of mathematics classrooms. Learning and Instruction, 17, 478-493

Gagné, N., \& Parks, S. (2013). Cooperative learning tasks in a Grade 6 intensive ESL class: Role 
of scaffolding. Language Teaching Research, 17, 188-209.

Gavin, M. B., \& Hofmann, D. A. (2002). Using hierarchical linear modeling to investigate the moderating influence of leadership climate. The Leadership Quarterly, 13, 15-33.

Gkonou, C., \& Miller, E. R. (2019). Caring and emotional labour: Language teachers' engagement with anxious learners in private language school classrooms. Language Teaching Research, 23, 372-387.

Goetz, T., Frenzel, A.C., Stoeger, H., \& Hall, N. C. (2010). Antecedents of everyday positive emotions: An experience sampling analysis. Motivation and Emotion, 34, 49-62.

Hatfield, E., Cacioppo, J. T., \& Rapson, R. L. (1994). Emotional contagion. New York: Cambridge University Press.

Horwitz, E. K. (1996). Even teachers get the blues: Recognizing and alleviating language teachers' feelings of foreign language anxiety. Foreign Language Annals, 29, 365-372.

Johnson, D.W., \& Johnson, R.T. (2009). An educational psychology success story: Social interdependence theory and cooperative learning. Educational Researcher, 38, 365-379

Kang, H. J., \& Williamson, V. J. (2014). Background music can aid second language learning. Psychology of Music, 42(5), 728-747.

Khajavy, G. H., Ghonsooly, B., Hosseini, A., \& Choi, C. W. (2016). Willingness to communicate in English: A microsystem model in the Iranian EFL Classroom Context. TESOL Quarterly, 50, 154-180.

Khajavy, G. H., MacIntyre, P., \& Barabadi, E. (2018). Role of the emotions and classroom environment in willingness to communicate: Applying doubly latent multilevel analysis in second language acquisition research. Studies in Second Language 
Acquisition, 40, 605-624.

Lee, M. (2014). Achievement Goals, Emotions, and Foreign Language Performance in German and Korean Students. (Unpublished Doctoral Dissertation). University of Munich. Munich, Germany.

Leung KC, Marsh HW, Craven RG, \& Abduljabbar AS. (2016). Measurement invariance of the self-description questionnaire II in a Chinese sample. European Journal of Psychological Assessment, 32, 128-139.

Lüdtke, O., Marsh, H. W., Robitzsch, A., \& Trautwein, U. (2011). A $2 \times 2$ taxonomy of multilevel latent contextual models: Accuracy-bias trade-offs in full and partial errorcorrection models. Psychological Methods, 16, 444-467.

MacIntyre, P. D., \& Gardner, R. C. (1994). The subtle effects of language anxiety on cognitive processing in the second language. Language Learning, 44, 283-305.

MacIntyre, P. D., Gregersen, T., \& Mercer, S. (2019). Setting an agenda for positive psychology in SLA: Theory, practice, and research. The Modern Language Journal, 103, $262-274$.

Marsh, H. W., \& O’Neill, R. (1984). Self-Description Questionnaire III: The Construct Validity of Multidimensional Self-Concept Ratings by Late Adolescents. Journal of Educational Measurement, 21, 153-174.

Marsh, H. W., L“udtke, O., Nagengast, B., Trautwein, U., Morin, A. J. S., Abduljabbar, A. S., \& K"oller, O. (2012). Classroom climate effects: Methodological issues in the evaluation of group-level effects. Educational Psychologist, 47, 106-124.

Marsh, H. W., L“udtke, O., Robitzsch, A., Trautwein, U., Asparouhov, T., Muth'en, B. O., 
\& Nagengast, B. (2009). Doubly-latent models of school contextual effects: Integrating multilevel and structural equation approaches to control measurement and sampling error. Multivariate Behavioral Research, 44, 764-802.

Marsh, H. W., Seaton, M., Trautwein, U., Lüdtke, O., Hau, K. T., O'Mara, A. J., \& Craven, R.G. (2008). The big-fish-little-pond-effect stands up to critical scrutiny: Implications for theory, methodology, and future research. Educational Psychology Review, 20, 319 350.

McDonald, R.P. (1970). Theoretical foundations of principal factor analysis, canonical factor analysis, and alpha factor analysis. British Journal of Mathematical and Statistical Psychology, 23, 1-21.

Möller, J., Zitzmann, S., Helm, F., Machts, N., \& Wolff, F. (2020). A Meta-Analysis of Relations Between Achievement and Self-Concept. Review of Educational Research, 90, 376-419.

Moody, E., McIntosh, D. N., Mann, L. J., \& Weisser, K. R. (2007). More than mere mimicry? The influence of emotion on rapid facial reactions to faces. Emotion, 7, 447457.

Morin, A. J. S., Marsh, H. W., Nagengast, B., \& Scalas, L. F. (2014). Doubly latent multilevel analyses of classroom climate: an illustration. Journal of Experimental Education, 82, 143-167.

Moskowitz, S., \& Dewaele, J-M. (2019). Is teacher happiness contagious? A study of the link between perceptions of language teacher happiness and student attitudes. Innovation in Language Learning and Teaching. Advanced online publication. 
Muthén, L. K., \& Muthén B. O. (1998 -2017). Mplus user's guide (8th ed.). Los Angeles, CA: Author.

Neumann, R., \& Strack, F. (2000). Mood contagion: The automatic transfer of mood between persons. Journal of Personality and Social Psychology, 79, 211-223.

Parkinson, B. (2011). Interpersonal emotion transfer: Contagion and social appraisal. Personality and Social Psychology Compass, 5, 428-439.

Parkinson, B. (2020). Intragroup emotion convergence: Beyond contagion and social appraisal. Personality and Social Psychology Review, 24, 121-140.

Parkinson, B., \& Manstead, A.S.R. (2015). Current emotion research in social psychology: Thinking about emotions and other people. Emotion Review, 7, 371-380.

Parkinson, B., \& Simons, G. (2009). Affecting others: Social appraisal and emotion contagion in everyday decision making. Personality and Social Psychology Bulletin, 35, 1071-1084.

Pawlak, M., Kruk, M., Zawodniak, J., \& Pasikowski, S. (2020). Investigating factors responsible for boredom in English classes: The case of advanced learners. System, 91, $102-122$.

Pekrun, R. (2006). The control-value theory of achievement emotions: Assumptions, corollaries, and implications for educational research and practice. Educational Psychology Review, 18, $315-341$.

Pekrun, R., Goetz, T., Frenzel, A. C., Barchfeld, P., \& Perry, R. P. (2011). Measuring emotions in students' learning and performance: the Achievement Emotions Questionnaire (AEQ). Contemporary Educational Psychology, 36, 36-48. 
Pekrun, R., Hall, N. C., Goetz, T., \& Perry, R. P. (2014). Boredom and academic achievement: Testing a model of reciprocal causation. Journal of Educational Psychology, 106(3), 696710.

Pekrun, R., \& Meier, E. (2011). Task value questionnaire. Unpublished manuscript, Department of Psychology, University of Munich. Munich, Germany.

Pekrun, R., Murayama, K., Marsh, H. W., Goetz, T., \& Frenzel, A. C. (2019). Happy fish in little ponds: Testing a reference group model of achievement and emotion. Journal of Personality and Social Psychology, 117(1), 166-185.

Pekrun, R., \& Perry, R. P. (2014). Control-value theory of achievement emotions. In R. Pekrun and L. Linnenbrink-Garcia (eds.), International Handbook of Emotions in Education (pp. 120-141). New York: Taylor and Francis.

People's Education (2016). Chuzhong Yingyu Xinkebiao. [New curriculum standard for middle school English textbooks]. Beijing, People's Education Press.

Phung, L. (2017). Task preference, affective response, and engagement in L2 use in a US university context. Language Teaching Research, 21, 751-766.

Putwain, D. W., Pekrun, R., Nicholson, L. J., Symes, W., Becker, S., \& Marsh, H. W. (2018). Control-value appraisals, enjoyment, and boredom in mathematics: A longitudinal latent interaction analysis. American Educational Research Journal, 55, $1339-1368$.

Raykov, T., \& Marcoulides, G. A. (2004). Using the Delta Method for Approximate Interval Estimation of Parametric Functions in Covariance Structure Models. Structural Equation Modeling, 11, 659-675. 
Reyes, M. R., Brackett, M. A., Rivers, S. E., White, M., \& Salovey, P. (2012). Classroom Emotional Climate, Student Engagement, and Academic Achievement. Journal of Educational Psychology. 104, 700-712.

Saito, K., Dewaele, J., Abe, M., \& In'nami, Y. (2018). Motivation, emotion, learning experience, and second language comprehensibility development in classroom settings: A cross-sectional and longitudinal study. Language Learning, 68, 709-743.

Sardegna, V. G., Lee, J. \& Kusey, C. (2018). Self-efficacy, attitudes, and choice of strategies for English pronunciation learning. Language Learning, 68, 83-114.

Scherer, K. R. (2013). The nature and dynamics of relevance and valence appraisals: Theoretical advances and recent evidence. Emotion Review, 5, 150-162.

Shao, K. Q., Nicholson, L. J., Kutuk, G., \& Lei, F. (2020a). Emotions and instructed language learning: Proposing a second language emotions and positive psychology model. Frontiers in Psychology, Advanced online publication.

\section{Doi: $10.3389 /$ fpsyg. 2020.02142}

Shao, K. Q., Pekrun, R., Marsh, H.W., \& Loderer, K. (2020b). Control-value appraisals, achievement Emotions, and foreign language performance: A latent interaction analysis. Learning and Instruction. Advanced online publication.

\section{Doi: 10.1016/i.learninstruc.2020.101356}

Shao, K. Q., Pekrun, R., \& Nicholson, L. J. (2019). Emotions in classroom language learning: What can we learn from achievement emotion research? System, 86, 102-121.

Shao, K. Q., Yu, W. H., \& Ji, Z. M. (2012). The relationship between EFL students' emotional intelligence and writing achievement. Innovation in Language Learning and 
Teaching, 7, 107-124.

Shao, K. Q., Yu, W. H., \& Ji, Z. M. (2013). An exploration of Chinese EFL students' emotional intelligence and foreign language anxiety. Modern Language Journal, 97, 919-931.

Shirvan, M.E., \& Taherian, T. (2018). Longitudinal examination of university students' foreign language enjoyment and foreign language classroom anxiety in the course of general English: latent growth curve modeling. International Journal of Bilingual Education and Bilingualism. Advanced online publication. Doi:

$10.1080 / 13670050.2018 .1441804$

Teimouri, Y. (2017). L2 selves, emotions, and motivated behaviors. Studies in Second Language Acquisition, 39, 681-709.

Teimouri, Y., Goetze, J., \& Plonsky, L. (2019). Second Language Anxiety and Achievement: A Meta-analysis. Studies in Second Language Acquisition, 41, 363-387. 

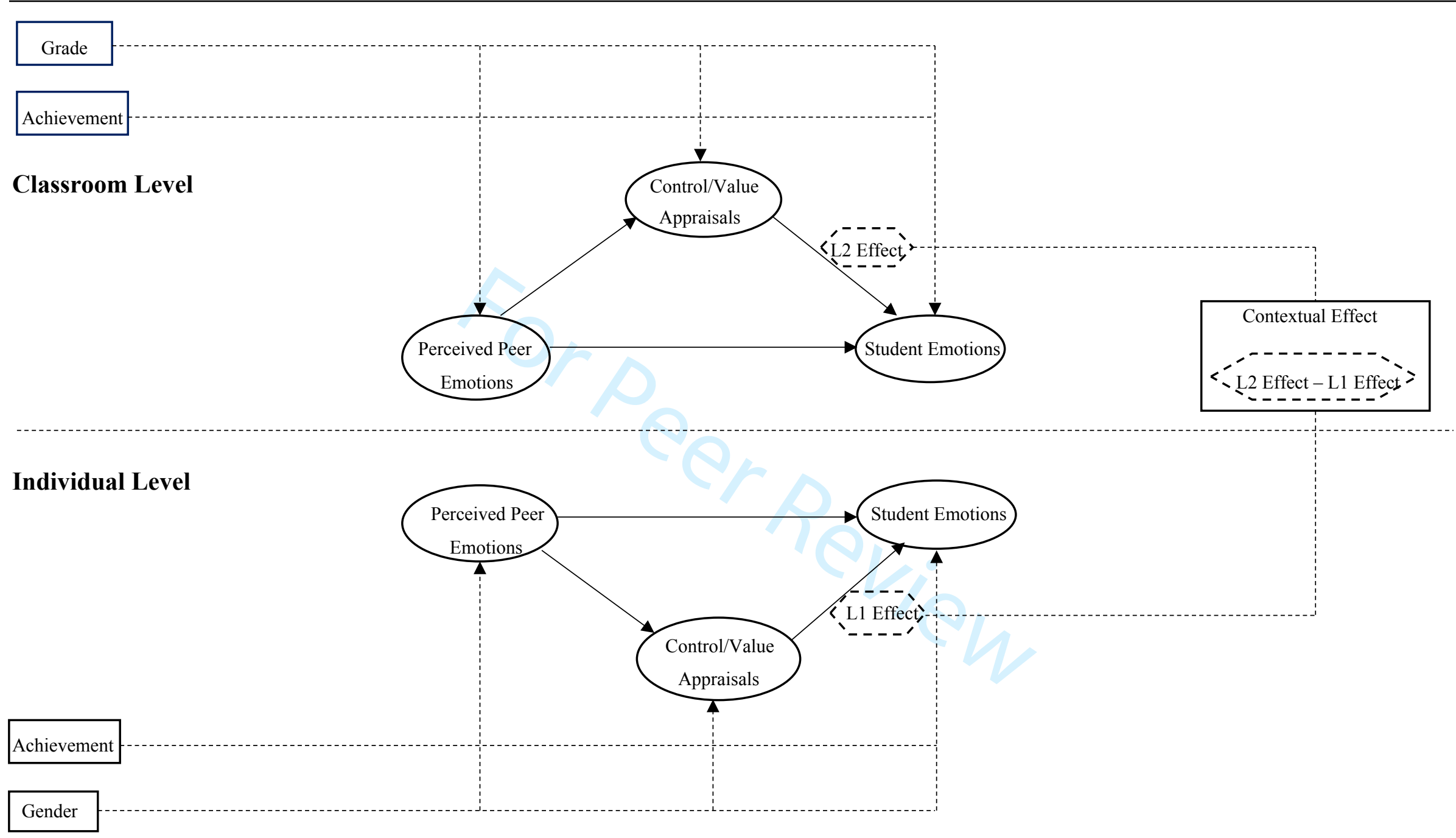

Figure 1. Multilevel structural equation model for relationships between perceived peer emotions, control-value appraisals and student emotions. Covariates and contextual effect were also depicted. 
Table 1

Descriptive Statistics for the Study Variables

\begin{tabular}{llcccc}
\hline Variable & $M$ & $S D$ & Range & Skewness & Kurtosis \\
\hline Perceived peer enjoyment & 3.62 & .95 & $5-25$ & -.25 & -.78 \\
Perceived peer anxiety & 2.56 & .97 & $5-25$ & .27 & -.54 \\
Perceived peer boredom & 2.03 & .84 & $5-25$ & .83 & .61 \\
Control appraisal & 3.03 & 1.08 & $6-30$ & -.09 & -.87 \\
Value appraisal & 3.82 & .85 & $6-30$ & -.88 & .42 \\
Student enjoyment & 3.57 & .91 & $5-25$ & -.24 & -.80 \\
Student anxiety & 2.70 & 1.00 & $5-25$ & .14 & -.67 \\
Student boredom & 2.04 & .94 & $5-25$ & .74 & -.22 \\
Performance & 93.06 & 20.53 & $0-120$ & -1.32 & 1.40 \\
\hline
\end{tabular}


Table 2

Manifest Correlations Among the Study Variables at two Levels

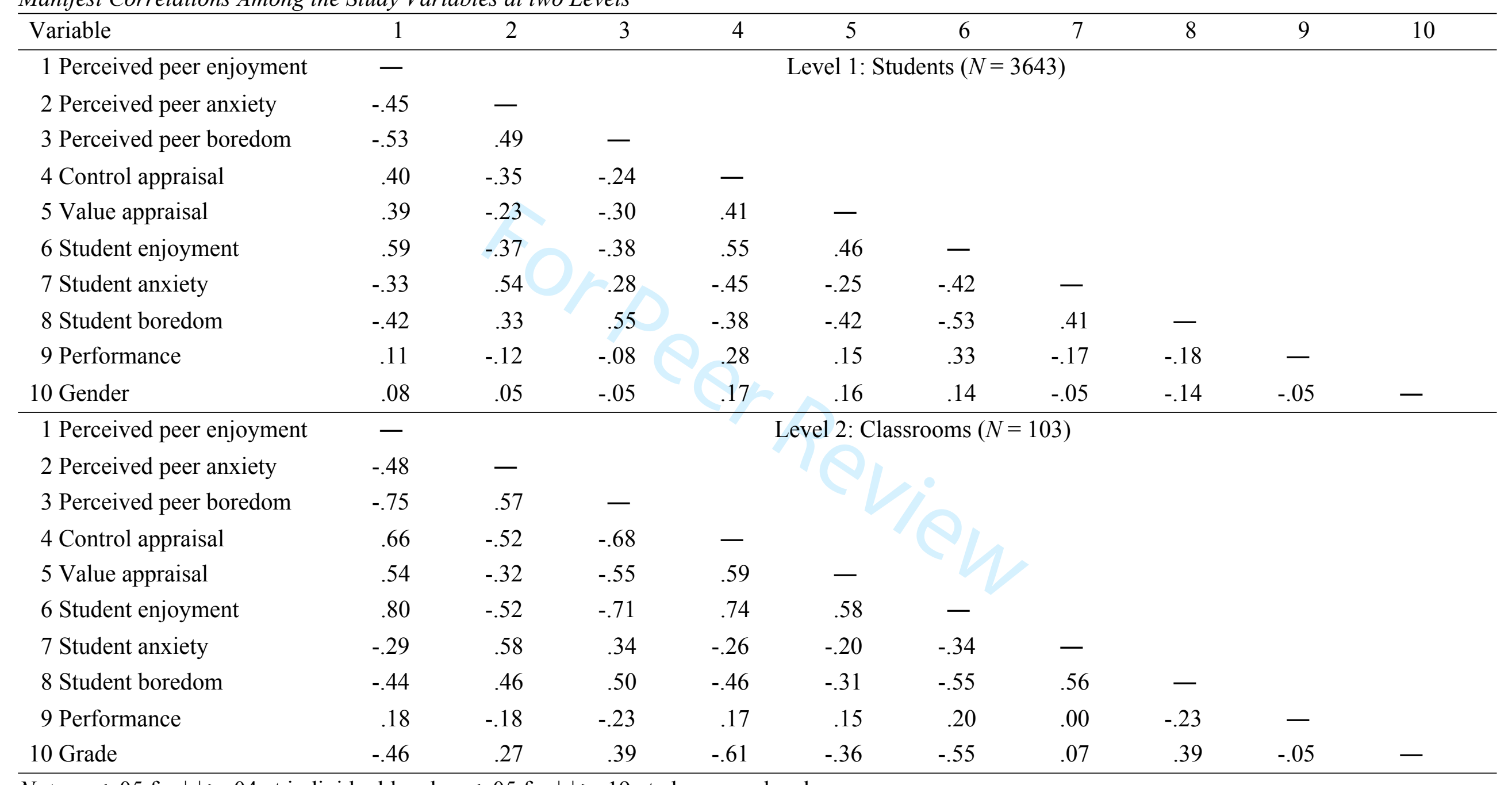

Note. $p<.05$ for $|r|>.04$ at individual level; $p<.05$ for $|r|>.19$ at classroom level. 
Table 3

Fit Indices for Multilevel CFA and SEM Models

\begin{tabular}{|c|c|c|c|c|c|c|c|c|c|c|}
\hline \multirow[b]{2}{*}{ Model } & \multicolumn{5}{|c|}{ Control Appraisal } & \multicolumn{5}{|c|}{ Value Appraisal } \\
\hline & $\chi^{2}$ & $d f$ & CFI & TLI & RMSEA & $\chi^{2}$ & $d f$ & CFI & TLI & RMSEA \\
\hline \multicolumn{11}{|l|}{$M L-C F A$} \\
\hline Enjoyment & 715.08 & 272 & .96 & .96 & .026 & 667.81 & 272 & .96 & .97 & .025 \\
\hline Anxiety & 675.34 & 272 & .97 & .97 & .024 & 687.76 & 272 & .97 & .97 & .026 \\
\hline Boredom & 743.81 & 272 & .96 & .95 & .027 & 693.07 & 272 & .96 & .95 & .026 \\
\hline \multicolumn{11}{|l|}{$M L-S E M$} \\
\hline Enjoyment & 827.76 & 240 & .96 & .95 & .027 & 735.61 & 240 & .96 & .96 & .025 \\
\hline Anxiety & 772.20 & 240 & .97 & .96 & .025 & 745.58 & 240 & .97 & .96 & .025 \\
\hline Boredom & 852.55 & 240 & .95 & .95 & .027 & 796.48 & 240 & .96 & .95 & .026 \\
\hline
\end{tabular}

Note. Each emotion indicates the model linking respective perceived peer emotion, control/value appraisals and students' corresponding emotion. $\chi^{2}=$ chi square test of model fit; $d f=$ degree of freedom; CFI = comparative Fit Index; TLI = Tucker-Lewis index; RMSEA = root mean square error of approximation. 
Table 4

Main Effects from the Final Multilevel SEM Models Presented in Figure 1

\begin{tabular}{|c|c|c|c|c|}
\hline & \multicolumn{2}{|c|}{ Control Appraisal } & \multicolumn{2}{|c|}{ Value Appraisal } \\
\hline & Est. (S.E.) & Std. (S.E.) & Est. (S.E.) & Std. (S.E.) \\
\hline \multicolumn{5}{|l|}{ L1 effects } \\
\hline Peer Enjoyment $\rightarrow$ Appraisal & $.46(.07)^{* * *}$ & $.45(.06)^{* * *}$ & $.62(.08)^{* * *}$ & $.55(.07)^{* * *}$ \\
\hline Appraisal $\rightarrow$ Student Enjoyment & $.35(.08)^{* * *}$ & $.39(.08)^{* * *}$ & $.36(.09)^{* * *}$ & $.43(.11)^{* * *}$ \\
\hline Peer Enjoyment $\rightarrow$ Student Enjoyment & $.48(.09)^{* * *}$ & $.51(.08)^{* * *}$ & $.41(.11)^{* * *}$ & $.44(.11)^{* * *}$ \\
\hline Peer Anxiety $\rightarrow$ Appraisal & $-.46(.06)^{* * *}$ & $-.40(.04)^{* * *}$ & $-.22(.04)^{* * *}$ & $-.25(.04)^{* * *}$ \\
\hline Appraisal $\rightarrow$ Student Anxiety & $-.27(.05)^{* * *}$ & $-.35(.06)^{* * *}$ & $-.16(.05)^{* * *}$ & $-.16(.05)^{* * *}$ \\
\hline Peer Anxiety $\rightarrow$ Student Anxiety & $.44(.06) * * *$ & $.51(.05)^{* * *}$ & $.54(.07)^{* * *}$ & $.62(.05)^{* * *}$ \\
\hline Peer Boredom $\rightarrow$ Appraisal & $-.34(.04)^{* * *}$ & $-.28(.03)^{* * *}$ & $-.52(.07)^{* * *}$ & $-.45(.05)^{* * *}$ \\
\hline Appraisal $\rightarrow$ Student Boredom & $-.19(.03)^{* * *}$ & $-.24(.04)^{* * *}$ & $-.35(.06)^{* * *}$ & $-.42(.07)^{* * *}$ \\
\hline Peer Boredom $\rightarrow$ Student Boredom & $.53(.04)^{* * *}$ & $.57(.03)^{* * *}$ & $.43(.06)^{* * *}$ & $.44(.06)^{* * *}$ \\
\hline \multicolumn{5}{|l|}{ L2 effects } \\
\hline Peer Enjoyment $\rightarrow$ Appraisal & $.42(.09)^{* * *}$ & $.14(.09)^{* * *}$ & $.70(.12)^{* * *}$ & $.21(.03)^{* * *}$ \\
\hline Appraisal $\rightarrow$ Student Enjoyment & $-.08(.11)$ & $-.03(.02)$ & $-.06(.10)$ & $-.02(.02)$ \\
\hline Peer Enjoyment $\rightarrow$ Student Enjoyment & $.58(.16)^{* * *}$ & $.21(.14)^{* * *}$ & $.46(.18)^{* * *}$ & $.17(.06)^{* * *}$ \\
\hline Peer Anxiety $\rightarrow$ Appraisal & $-.52(.11)^{* * *}$ & $-.13(.03)^{* * *}$ & $-.46(.12)^{* * *}$ & $-.13(.06)^{*}$ \\
\hline Appraisal $\rightarrow$ Student Anxiety & $.25(.11)^{*}$ & $.07(.03)^{*}$ & $.13(.06)$ & $.07(.04)$ \\
\hline Peer Anxiety $\rightarrow$ Student Anxiety & $.59(.13) * * *$ & $.21(.04)^{* * *}$ & $.58(.12)^{* * *}$ & $.18(.04)^{* * *}$ \\
\hline Peer Boredom $\rightarrow$ Appraisal & $-.43(.08)^{* * *}$ & $-.15(.03)^{* * *}$ & $-.67(.22)^{* * *}$ & $-.21(.07)^{* * *}$ \\
\hline Appraisal $\rightarrow$ Student Boredom & $.13(.21)$ & $.03(.05)$ & $.36(.09)^{* * *}$ & $.18(.05)^{* * *}$ \\
\hline Peer Boredom $\rightarrow$ Student Boredom & $.53(.17)^{* * *}$ & $.21(.07)^{* * *}$ & $.54(.13)^{* * *}$ & $.21(.06)^{* * *}$ \\
\hline
\end{tabular}

Note. ${ }^{*} p<.05 .{ }^{* *} p<.01 .{ }^{* * *} p<.001$; Est. $=$ unstandardized parameter estimate; S.E. $=$ standard error of the estimate; Std. $=$

standardized parameter estimate. 


\section{Social Psychological Accounts of Peer Emotion Transfer in EFL Classrooms: A Doubly Latent Multilevel Analysis}

- Supplemental Materials -

This supplementary document contains all self-report items used in the present study.

\section{Perceived Peer Emotions}

同学情绪感知

The following questions ask your perceptions of your classmates' emotions in this

English class during recent two weeks. There are no right or wrong answers. Please write a corresponding number to indicate how you perceive their feelings. 下列问题涉及你对你们班同学最近两周上这门英语课时的情绪的感知。回答无对错之 分。请用相应的数字表明你对他们情绪的感知。

\section{Enjoyment:}

1. My classmates enjoy being in this English class. 我们班同学喜欢上这门英语课。

2. My classmates' enjoyment of this English class makes them want to participate. 从这门英语课中得到的乐趣让我们班同学很愿意参与它。

3. My classmates get excited about listening to the English teacher in this class. 
能听英语老师讲这门课让我们班同学十分兴奋。

4. My classmates enjoy participating this English class so much that they get energized. 我们班同学很喜欢上这门英语课, 因此他们在课堂上很活跃。

5. My classmates are looking forward to learning a lot in this English class. 我们班同学期待从这门英语课中学到很多东西。

\section{Anxiety:}

1. My classmates feel nervous in this English class. 我们班同学在上这门英语课时会感到紧张。

2. My classmates get scared that they might say something wrong in this English class. 我们班同学害怕上英语课时会答错问题。

3. My classmates get tense when communicating with the teacher in English. 在课堂上与老师用英语对话时, 我们班同学感到紧张。

4. My classmates worry whether they may be called upon by the English teacher to answer questions they don't understand. 我们班同学担心英语老师会叫他们回答不懂的问题。

5. My classmates get nervous about speaking English in front of other students. 在其他同学面前说英语让我们班同学感到紧张。

\section{Boredom:}

1. My classmates get bored in this English class. 我们班同学上这门英语课时会感到厌倦。

2. My classmates find this English class fairly dull. 我们班同学觉得这门英语课很无聊。 
3. My classmates feel so bored that they can't wait for this English class to end. 在这门英语课上, 我们班同学感到十分厌倦, 迫不及待等着下课。

4. My classmates get so bored by this English class that their mind begin to wonder. 在这门英语课上，我们班同学由于感到庈倦而在思想上开小差。

5. My classmates think about what else they might be doing rather than sitting in this boring English class.

我们班同学在想还能做些什么其他的事情, 而不是坐在这无聊的英语课上。

\section{Control-Value Appraisals}

控制-价值评估

The following questions pertain to your beliefs and attitudes in English during recent two weeks. There are no right or wrong answers, please be open and honest.

下列问题涉及你在最近两周对学习英语的信念和态度。回答无对错之分, 请坦诚作答。

\section{Academic Self-Concept in English}

\section{英语学习自我概念}

1. English is one of my best subjects.

英语是我最擅长的科目之一。

2. I get good marks in English.

我的英语考试分数好。

3. Work in English is easy for me.

学习英语对我来说比较简单。 
4. I have always done well in English.

我英语学得一直很好。

5. I do badly in tests of English.

我的英语考试分数差。

6. I learn things quickly in English classes.

我在英语课上学东西很快。

\section{Academic Value in English}

英语学习价值

1. I find learning English is very interesting.

我觉得学习英语很有趣。

2. It is important to me to get good grades in English.

在英语考试中取得好的分数对我很重要。

3. I think learning English is very useful for me. 我认为学习英语很有用。

4. I like reading English texts.

我喜欢阅读英语课本。

5. It is important to me not to get bad grades in English.

在英语考试中不能考得糟糕对我很重要。

6. Learning more about English is useful for my life.

学习更多的英语对我的生活很有用。

\section{Student Classroom Achievement Emotions}

学生课堂学习情绪 
The following questions pertain to emotions you may experience in this English class during recent two weeks. There are no right or wrong answers, please write a corresponding number to indicate how you feel in this class.

下列问题涉及你在最近两周上这门英语课时可能会感受到的情绪。回答无对错之分。 请在空格处用相应的数字表明你在上这门英语课时的感受。

\section{Enjoyment:}

1. I enjoy being in this English class.

我喜欢上这门英语课。

2. My enjoyment of this English class makes me want to participate.

从这门英语课中得到的乐趣让我很愿意参与它。

3. It's so exciting that I could sit in this class for hours listening to the English teacher.

能听英语老师讲这门课让我十分兴奋。

4. I enjoy participating so much that I get energized. 我很喜欢上这门英语课, 因此我在课堂上很活跃。

5. I am looking forward to learning a lot in this English class. 我期待从这门英语课中学到很多东西。

\section{Anxiety:}

1. I feel nervous in this English class. 我在上这门英语课时会感到紧张。

2. I get scared that I might say something wrong in this English class. 我害怕上英语课时会答错问题。 
3. I get tense when communicating with the teacher in English. 在课堂上与老师用英语对话时, 我感到紧张。

4. I worry whether I may be called upon by my English teacher to answer questions I don't understand.

我担心英语老师会叫我回答不懂的问题。

5. I get nervous about speaking English in front of other students.

在其他同学面前说英语让我感到紧张。

\section{Boredom:}

1. I get bored in this English class.

我上这门英语课时会感到厌倦。

2. I find this English class fairly dull. 我觉得这门英语课很无聊。

3. I feel so bored that I can't wait for this English class to end. 在这门英语课上, 我感到十分厌倦, 迫不及待等着下课。

4. Because I get bored, my mind begins to wonder. 在这门英语课上，我因感到厌倦而在思想上开小差。

5. I think about what else I might be doing rather than sitting in this boring English class.

我在想还能做些什么其他的事情, 而不是坐在这无聊的英语课上。 